\title{
The Design of a Semi-Prefabricated LVL-Concrete Composite Floor
}

\author{
David Yeoh $^{1,2}$ and Massimo Fragiacomo ${ }^{3}$ \\ ${ }^{1}$ Faculty of Civil and Environmental Engineering, Universiti Tun Hussein Onn Malaysia, Parit Raja, 86400 Batu Pahat, Malaysia \\ ${ }^{2}$ Department of Civil and Natural Resources, University of Canterbury, 8140 Christchurch, New Zealand \\ ${ }^{3}$ Department of Architecture, Design and Urban Planning, Faculty of Architecture, University of Sassari, Palazzo del Pou Salit, \\ Piazza Duomo 6, 07041 Alghero, Italy \\ Correspondence should be addressed to David Yeoh, david@uthm.edu.my
}

Received 2 April 2012; Accepted 29 May 2012

Academic Editor: Bassam A. Izzuddin

Copyright ( 2012 D. Yeoh and M. Fragiacomo. This is an open access article distributed under the Creative Commons Attribution License, which permits unrestricted use, distribution, and reproduction in any medium, provided the original work is properly cited.

This paper describes the design of a novel semi-prefabricated LVL-concrete composite floor that has been developed in New Zealand. In this solution, the floor units made from LVL joists and plywood are prefabricated in the factory and transported to the building site. The units are then lifted onto the supports and connected to the main frames of the building and to the adjacent units. Finally, a concrete topping is poured on top of the units in order to form a continuous slab connecting all the units. Rectangular notches cut from the LVL joists and reinforced with coach screws provide the composite action between the concrete slab and the LVL joists. This system proved to be an effective modular solution that ensures rapid construction. A design procedure based on the use of the effective flexural stiffness method, also known as the "gamma method" is proposed for the design of the composite floor at ultimate and serviceability limit states, in the short and long term. By comparison with the experimental results, it is shown that the proposed method leads to conservative design. A step-by-step design worked example of this novel semi-prefabricated composite floor concludes the paper.

\section{Introduction}

Timber-concrete composite (TCC) floor system is a construction technique where a concrete slab is mechanically connected to its supporting timber joists using either notches cut from the timber or suitable mechanical fasteners. The concrete can be cast in-situ, or, alternatively, the fasteners can be inserted into a prefabricated concrete slab to provide on-site connection to the timber. The shear connectors provide composite action which utilizes the advantages of both materials: tensile and bending resistance of timber and compressive strength of concrete [1]. In an effort to introduce new applications of timber in multistorey buildings in New Zealand, medium- to long-span TCC floors of 8 to $10 \mathrm{~m}$ have been proposed with the innovative use of laminated veneer lumber (LVL) as the timber joist in TCC as opposed to the normally used sawn timber or glued laminated lumber (glulam). An extensive research programme has been performed at the University of Canterbury aimed to develop a novel semi-prefabricated LVL-concrete composite floor system $[2,3]$. The adopted connection system is made of notches cut in the LVL, reinforced with coach screws, and filled with concrete. The system was proved to be very effective, and high degree of composite action was attained with few notches [4]. An important question to address is the development of a simple design procedure suitable for use by practicing engineers. Although several papers provide some information [5-9], the design of TCC is not explicitly dealt with by most of the timber standards around the world. The only regulation mentioning TCCs is Eurocode 5, Part 2 [10], and Eurocode 5, Part 1-1, Annex B [11] where, however, no comprehensive design procedure is given. Because the connection between the interlayer, concrete, and timber, is normally semirigid which will result in a relative slip between the bottom fibre of the concrete and the upper fibre of the timber, the assumption of plane sections' remaining 
plane does not apply to the composite section as a whole. Therefore, the method of the transformed section from the conventional principles of structural analysis cannot be used. In order to account for the partial composite action resulting from the flexibility of the shear connection, the approximate solution using an effective bending stiffness (also known as the "gamma" method) derived by [12] for timber-timber composite beams with flexible connection proposed in the Annex B of the Eurocode 5 [11] is used [5]. Such a procedure, however, has been proposed for composite beams with "diffused" connection system made of either continuous connectors or many fasteners at a small spacing. Furthermore, there is little information on how the design at ultimate and serviceability limit state should allow for creep deformation and stress redistributions over time due to rheological phenomena of the component materials (concrete, timber, and connection system).

The paper addresses these important issues by describing a method suitable for design of this novel semi-prefabricated LVL-concrete composite floor. The method is compared with experimental results demonstrating that it is conservative. A detailed worked example of this design is then provided as an aid for practicing engineers.

\section{Semi-Prefabricated LVL-Concrete Composite Floor}

Floors are a crucial part of multi-storey timber buildings. There are several advantages of TCC floors over timber-only floors, including greater stiffness, less susceptibility to vibrations, better seismic performance, higher fire resistance, and, last but not least, better acoustic separation. An increasing range of TCC systems has been developed, including cast-insitu, semi-prefabricated, and fully prefabricated floors [13].

A semi-prefabricated composite floor system built with LVL beams which act as floor joists and a plywood interlayer as permanent formwork has been proposed for the New Zealand building industry (Figure 1) [2]. The connection system has notches cut from the LVL joist and reinforced with a coach screw to provide more ductile behaviour during failure and to increase the shear strength. These notches are cut in the beams before the plywood interlayer is nailed on. Toothed metal plate is another preferred connection where no cutting of notches is required which allows fast and easy installation of the connection with the help of an industrial hydraulic press [4]. This floor system is comprised of a typical $2400 \mathrm{~mm}$ wide " $\mathrm{M}$ " section unit with one $63 \times 400 \mathrm{~mm}$ LVL joist on each side and a double LVL in the centre, with spans between 8 and $10 \mathrm{~m}$ requiring 6 to 10 connectors along the length of each joist to provide adequate composite action. Each unit weighs approximately $8 \mathrm{kN}$, resulting in a lightweight component that is easy to be transported and craned [2]. This system was used as a floor in a large-scale, two-storey, experimental posttensioned timber building (Figure 2) through a combined initiative of the University of Canterbury and Structural Timber Innovation Company (STIC) [14]. The building was constructed to aid the development of connection details, to provide cost and construction sequencing information, and to evaluate

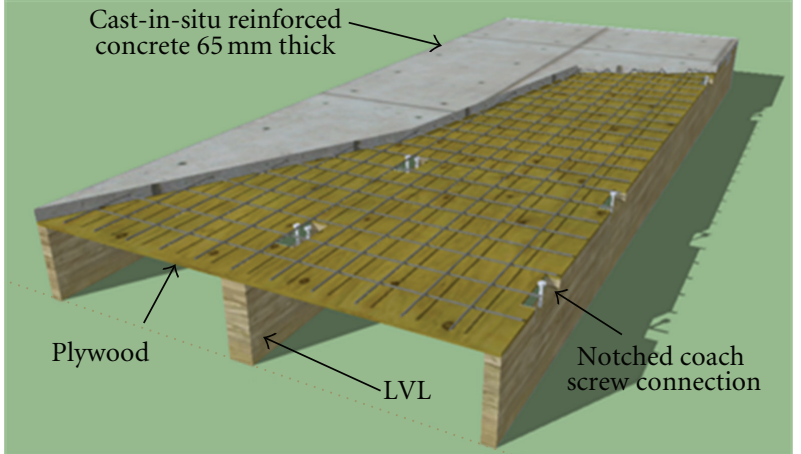

FIGURE 1: "M" section semi-prefabricated LVL-concrete composite floor system.

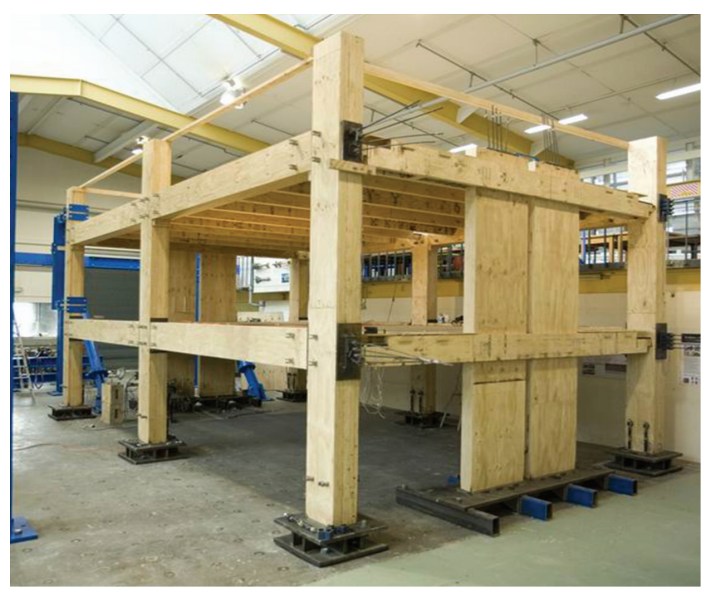

FIGURE 2: Experimental posttensioned timber building in the laboratory of the University of Canterbury with TCC floors.

the earthquake performance of the structural system. This same test building, after being subjected up to magnitude 8 earthquake ground motions in the laboratory resulting in no structural damage, was dismantled and reassembled within the University of Canterbury campus, now called the EXPAN building (Figure 3 ). The building subsequently underwent 3 significant real earthquakes occurred in Christchurch and emerged without any structural damage [15].

The TCC floor units were prefabricated and delivered on site by commercial Glulam (glued laminated timber) manufacturers. At the time of this exercise, New Zealand timber fabricators did not have fully mechanized production capability yet and relied mainly on handheld tools which resulted in high fabrication costs for the TCC floor units. Approximately 25\% of the total fabrication cost was attributed to labour which calls for an improvement in the New Zealand timber manufacturing processes. Overall, the TCC floor units contributed to $42 \%$ of the total construction cost. On-site assembly was rapid (Figures 3 and 4). Each TCC floor unit was held by overhead crane for approximately 2 minutes, equating to a floor coverage rate of $486 \mathrm{~m}^{2} /$ hour. These TCC floor units were light enough to be manoeuvred manually. 


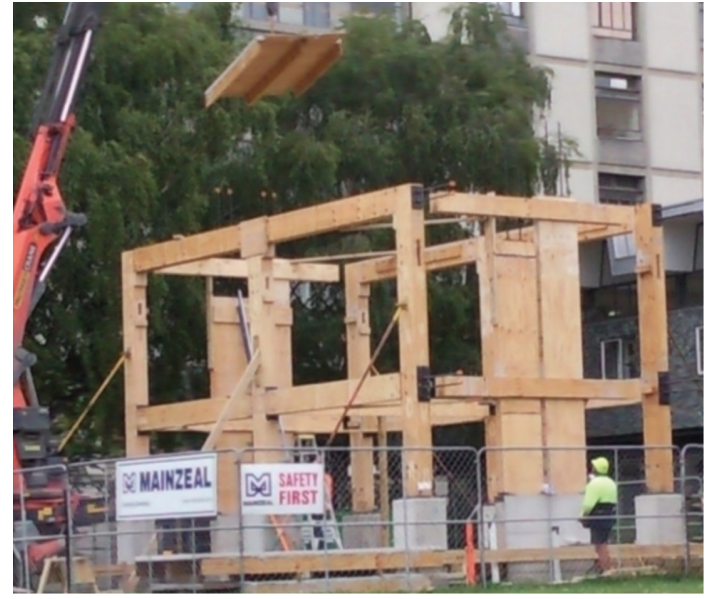

FIGURE 3: Reassembly of experimental building with TCC floors within the University of Canterbury campus, now known as the EXPAN building.

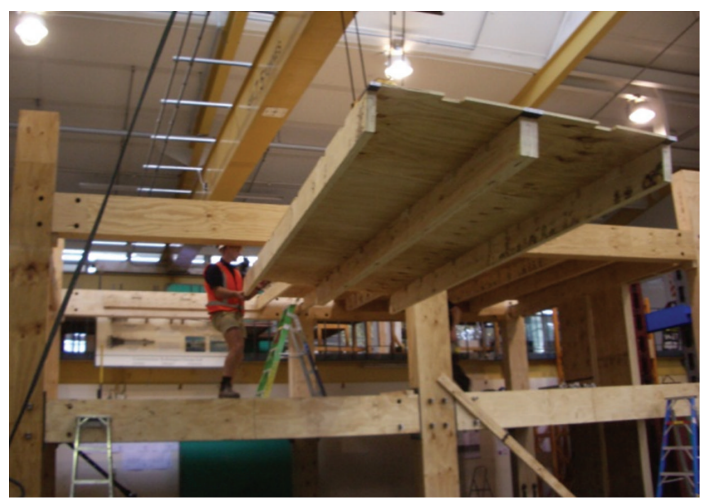

FIGURE 4: On-site assembly of floor unit in laboratory.

These floor units were supported on specially designed corbel seat consisting of $20 \mathrm{~mm}$ thick steel plates and $200 \mathrm{~mm}$ long 14-gauge type 17 wood screws (Figure 5) that allows fastening of the connections from the top which further increases the construction rate and ensure a modular system [16]. Such support seating is able to accommodate large seismic deformations and maintain significant inplane seismic forces to meet the New Zealand earthquake requirements [17]. Joist hanger support connection with type 17 screws and in-plane floor shear transfer using either coach screws inserted in the lateral face of the beam or reinforcing bars connected to fasteners in the solid wall using threaded couplers have been proposed in the literature $[18,19]$. Steel mesh is used to provide shrinkage control for a typical $65 \mathrm{~mm}$ thick cast- in-situ concrete slab. The units can be propped while the concrete cures, or alternatively in an unpropped solution, the LVL joists can be precambered. Propping of the joists will incur extra cost and interruption to the builders on site. Conversely, precambering of the joists will perform the same result although it is not particularly practical. Precambering of the LVL joists can be achieved in two ways: (1) cutting a radius in the LVL joist during the

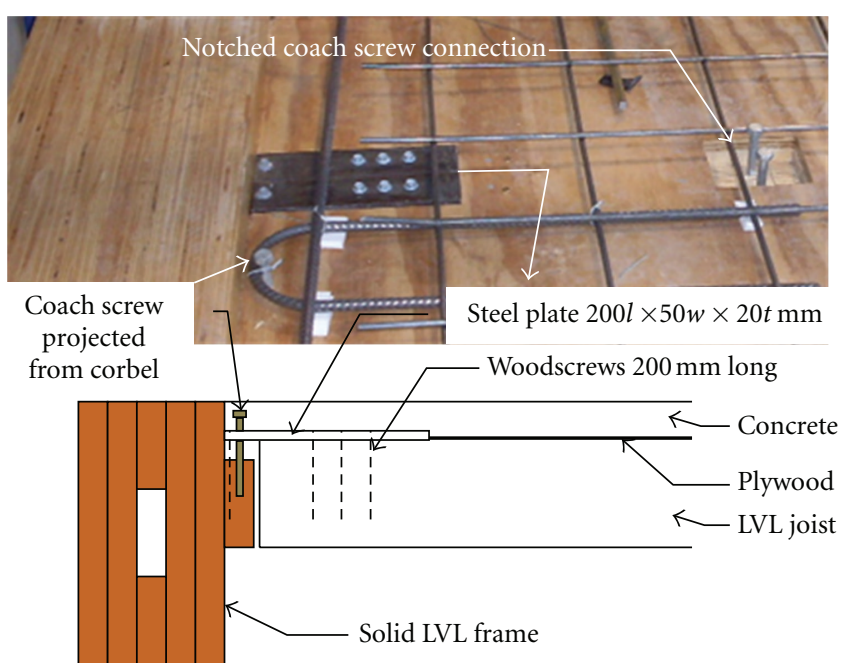

Figure 5: Support connection details.

production of the LVL or (2) during the prefabrication of the units, the LVL joists are clamped downwards at each end over a central support, forcing the joints to bend, then the permanent formworks, in this case, the plywood, are nailed or screwed to the LVL flange. This precambering solution on TCC floors has been introduced in the current College of Creative Arts Project at the Massey University in Wellington [20]. Another available solution is to increase the size of the LVL joist in order to minimise the effect of an unpropped floor. The final choice, however, would depend on the cost and savings achievable from each of the aforementioned solutions.

Advantages of this solution include (1) ease of transport and lifting of the panels due to their low weight (2) fast installation and easy positioning the panels without the need of a crane once they are lifted in place (3) construction of a monolithic concrete slab with better in-plane strength and stiffness, and no need for additional connections between adjacent panels (4) high strength and stiffness achievable with reduced number of connectors, due to the effectiveness of the notched connection detail (5) possibility to construct medium- to long-span floors, in the range of 8 to $12 \mathrm{~m}$ and therefore, (6) a system capable of competing with traditional precast concrete solutions. One disadvantage is the need to introduce a "wet" component (the fresh concrete) on the building site, where all other components are "dry" for a multi-storey timber building.

\section{Basics of Design}

The design of TCC beams has to be carried out in order to satisfy both serviceability (SLS) and ultimate limit states (ULS) in the short and long term (the end of the service life). The ULS is checked by comparing the maximum shear force in the connection, the maximum stress in concrete, and the combination of axial force and bending moment in timber with the corresponding resisting design values. The most important serviceability verification is 


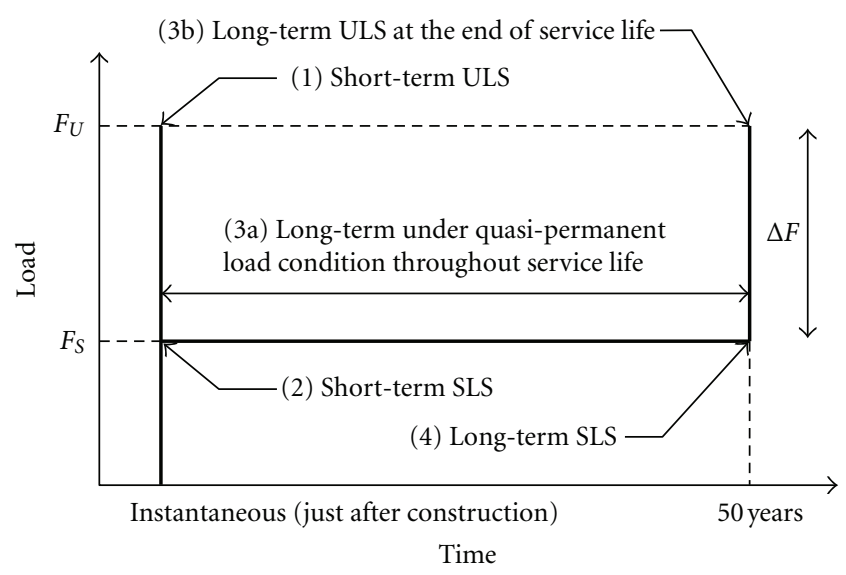

FIgURE 6: Limit state design of TCC beams for verifications in the short- and long-term.

the control of maximum deflection, which is used also for an indirect verification of the susceptibility of the floor to vibration, as suggested by AS/NZS 1170 Part 0 [21]. Two types of problem have to be addressed when evaluating stress and deflection of a TCC beam: (1) the flexibility of connection which leads to partial composite action and (2) the time-dependent behaviour such as creep, mechanosorption, shrinkage/swelling, thermal and moisture strains of timber and concrete, and creep and mechanosorption of the connection system, which cause additional deformations and stress redistribution over time among the different materials that should be taken into account in both serviceability and ultimate limit-state designs. An elastic analysis using the gamma method is applied for the short-term (instantaneous) verifications, while the "Effective Modulus Method" recommended in [5] is used for the long-term verifications in order to account for the effect of creep of the different materials.

The limit-state design of TCC beam should be checked in both the short and long term, as illustrated in Figure 6 . The complete design procedure should cover the following verifications [6]: (1) ULS in the short term, where the structure is under maximum load (i.e., $F_{d, u}=1.35 G+1.5 \mathrm{Q}$ in accordance with Eurocode 0 [22]) applied instantaneously just after construction; (2) SLS in the short term, where the deflection is verified upon the application of imposed load (i.e., only $Q$ that is not factored); (3) ULS in the long term, where the quasi-permanent load condition (i.e., $F_{d, p}=$ $G+0.3 Q$ in accordance with Eurocode 0 [22]) is applied throughout the service life of the structure and the remaining part of the ultimate load (i.e., $\Delta F=F_{d, u}-F_{d, p}=0.35 G+$ $1.2 Q$ ) is applied at the end of the service life; (4) SLS in the long term at the end of the service life, where the time dependent phenomena (creep) in the materials are evaluated under the quasi-permanent load condition $\left(F_{d, p}=G+0.3 Q\right)$ considered as applied throughout the service life and the instantaneous effects are produced by the difference between the rare $\left(F_{d, r}=G+Q\right)$ and the quasi-permanent $\left(F_{d, p}=\right.$ $G+0.3 Q)$ load condition $\left(F_{d, r}-F_{d, p}=(1-0.3) Q\right)$.

The ULS long-term verifications are theoretically indispensable for the reason that TCC structures are internally statically indeterminate structure made from three components, concrete, timber, and connection, each of them characterized by a different creep coefficient. Since the creep coefficients have different trend in time, they will lead to a redistribution of strains and stresses over time in the different materials. This implies the dependency of the load-carrying capacity on the time when it is evaluated and therefore, the need to carry out ULS verifications at different times (the assembling time, where no creep deformation has developed, and the end of the service life, when all materials have crept differently and stress redistribution has taken place in the composite beam). Furthermore, the concrete shrinkage and environmental variations will induce additional stresses and deflections which have not been considered in the design and for which some studies are in progress [23-25]. On the other hand, the SLS verifications in the long term considering both the quasi-permanent and rare combinations have been recommended by Eurocode 5 Part 1-1 [11] assigning a limit from $1 / 150$ to $1 / 300$ of the span length. However, SLS limits are less stringent than ULS limits depending on the function of the structure and requirement of the client.

\section{Flexibility of Connection}

Since most of the connection systems exhibit non linear shear force-relative slip relationship, Ceccotti [1] proposed to define two different values of slip modulus:

$$
\begin{aligned}
& K_{s}=\frac{0.4 R_{m}}{v_{0.4}}, \\
& K_{u}=\frac{0.6 R_{m}}{\nu_{0.6}},
\end{aligned}
$$

where $R_{m}$ is the mean shear strength obtained from a push-out test and $\nu_{0.4}$ and $\nu_{0.6}$ are slips measured under a shear load equal to $0.4 R_{m}$ and $0.6 R_{m}$, respectively. The quantities $K_{s}$ and $K_{u}$ are therefore secant slip moduli that are employed, respectively, for serviceability and ultimate limit state verifications (Figure 7). They should be evaluated by performing push-out experimental tests on small TCC blocks in accordance with EN 26891 [26] such as those found in the literature $[4,8]$.

If experimental results for the connection properties are not available, the formulas provided by Eurocode 5, Part 11 [11] for timber-timber connection systems can be used. More specifically, the slip modulus for serviceability and ultimate limit state can be calculated using semi empirical formulas such as

$$
\begin{gathered}
K_{s}=\frac{\rho_{m}^{1.5} d}{23}, \\
K_{u}=\frac{2}{3} K_{s},
\end{gathered}
$$

for timber-to-timber connections with dowels, bolts, screws, or pre-drilled nails, where $\rho_{m}, d$ signify the mean density of timber and fastener diameter, respectively. The slip modulus of a concrete-timber connection can then be conservatively estimated by doubling up the values of $K_{s}$ and $K_{u}$ [11]. 


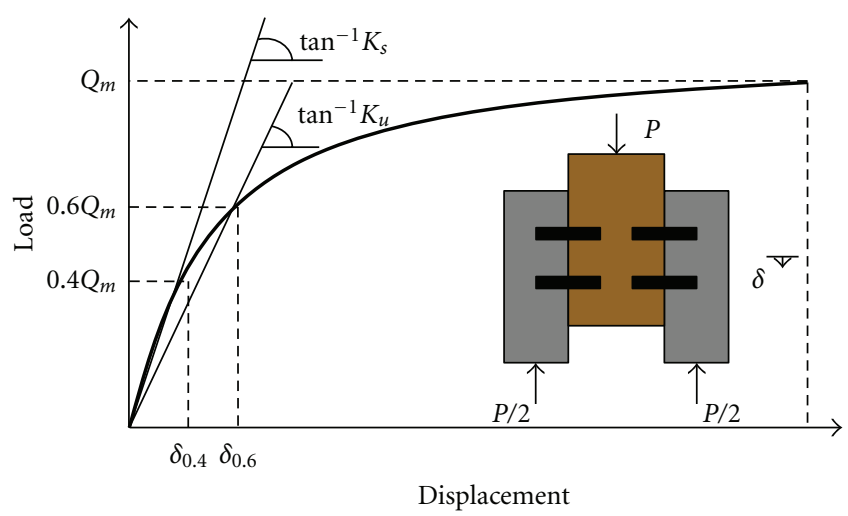

FIGURE 7: Evaluation of the secant slip moduli of connection for serviceability and ultimate limit states by performing a push-out test.

The shear strength of a timber-to-timber connection can be calculated using the European yielding model as derived by Johansen [27] and subsequently modified in the Eurocode 5 to account for friction and rope effect. The shear strength of a concrete-to-timber connection can then be conservatively estimated by increasing the aforementioned values by $20 \%$, as suggested by a former version of the Eurocode 5, Part 2 [10]. Studies recently performed $[28,29]$, however, showed that significant errors may be introduced using the analytical approach described above and recommended that experimental push-out tests be performed to fully characterize the connection system.

\section{Design Formulae}

The elastic formulas for solving the TCC beam are reported herein:

$$
\begin{gathered}
(E I)_{\mathrm{ef}}=E_{1} I_{1}+E_{2} I_{2}+\gamma_{1} E_{1} A_{1} a_{1}^{2}+\gamma_{2} E_{2} A_{2} a_{2}^{2}, \\
\gamma_{1}=\frac{1}{1+\pi^{2} E_{1} A_{1} s_{\mathrm{ef}} / K l^{2}}, \\
\gamma_{2}=1, \\
A_{i}=b_{i} h_{i} \quad \text { with } i=1,2, \\
I_{i}=\frac{b_{i} h_{i}^{3}}{12} \quad \text { with } i=1,2, \\
a_{1}=\frac{\gamma_{2} E_{2} A_{2} H}{\gamma_{1} E_{1} A_{1}+\gamma_{2} E_{2} A_{2}}, \\
a_{2}=\frac{\gamma_{1} E_{1} A_{1} H}{\gamma_{1} E_{1} A_{1}+\gamma_{2} E_{2} A_{2}}, \\
H=\frac{h_{1}}{2}+a+\frac{h_{2}}{2}, \\
s_{\mathrm{ef}}=0.75 s_{\min }+0.25 s_{\max }
\end{gathered}
$$

$$
\begin{gathered}
u=\frac{5 F_{d}^{*} l^{4}}{384(E I)_{\mathrm{ef}}}, \\
\sigma_{m, i}(x)=\frac{1}{2} \cdot \frac{E_{i} a_{i} M^{*}(x)}{(E I)_{\mathrm{ef}}}, \\
\sigma_{1}(x)=-\frac{\gamma_{1} E_{1} a_{1} M^{*}(x)}{(E I)_{\mathrm{ef}}}, \\
\sigma_{2}(x)=\frac{\gamma_{2} E_{2} a_{2} M^{*}(x)}{(E I)_{\mathrm{ef}}}, \\
N_{i}^{*}(x)=\sigma_{i}(x) \cdot A_{i}, \\
M_{i}^{*}(x)=\sigma_{m, i}(x) \cdot Z_{i}, \\
V_{2}^{*}(x)=V^{*}(x), \\
F^{*}(x)=\frac{\gamma_{1} E_{1} A_{1} a_{1} s(x)}{(E I)_{\mathrm{ef}}} \cdot V^{*}(x),
\end{gathered}
$$

where the subscripts 1 and 2 refer to concrete and timber respectively (see Figure 8 for notations), $E$ and $K$ are Young's modulus of material and slip modulus of connection, respectively; $G, A$, and $I$ denote the centroid, area and the second moment of area of the $i$ th cross-section, respectively; $Z$ is the section modulus of the $i$ th cross-section; $(E I)_{\mathrm{ef}}$ is the effective flexural stiffness of the composite beam; $u$ is the mid span vertical displacement, evaluated for simply supported beams, the most common case; $F_{d}^{*}$ is the design load combination, uniformly distributed along the beam; $\sigma_{1}$ and $\sigma_{2}$ are the stress components due to the axial force in concrete and timber, respectively, $\sigma_{m, 1}$ and $\sigma_{m, 2}$ are the maximum stress components due to the bending moment in concrete and timber, respectively; $N_{i}^{*}$ and $M_{i}^{*}$ are the demand of axial force and bending moment in the $i$ th component, respectively, $V_{2}^{*}$ is the shear force demand in timber, evaluated by assuming that the timber beam resists the entire shear force of the composite beam; $F^{*}$ is the shear force demand in the connection system; $s$ is the spacing between the connectors; $V^{*}$ and $M^{*}$ are the demand of shear force and bending moment in the composite beam, respectively, $x$ is the abscissa along the beam axis where the stresses and internal forces are being evaluated; $s_{\min }, s_{\max }$, and $s_{\text {ef }}$ are the minimum, maximum, and effective spacing of connectors, respectively. An issue for TCC beams with notched connection details is whether the above equations derived for "diffuse" connection lead to accurate solutions, and how the minimum and maximum connector spacing should be chosen. The recommended values are indicated in Figure 9.

The red circles in Figure 8 top point out the discontinuity of the strain and stress diagrams along the depth of the composite beam, due to the flexibility of the shear connection. Equation (4) are used for design in the short term of the composite beam. The different stiffness properties of the connection system due to the non-linear mechanical behaviour are taken into account by using the slip modulus $K_{s}$ given by (1) for serviceability limit-state verifications, 
whilst the slip modulus $K_{u}$ given by (2) is used for ultimate limit state verifications.

\section{Time-Dependent Behaviour}

The creep of the concrete flange, timber beam, and connection system can be accounted for, in long-term verifications, by replacing the elastic moduli of concrete $E_{1}$ and timber $E_{2}$, and the slip modulus of connection $K$ with the effective moduli $E_{1, \text { eff }}, E_{2, \text { eff }}$, and $K_{\text {eff }}$ given by

$$
\begin{gathered}
E_{1, \mathrm{eff}}=\frac{E_{1}}{1+\phi_{1}\left(t, t_{0}\right)}, \\
E_{2, \mathrm{eff}}=\frac{E_{2}}{1+\phi_{2}\left(t-t_{0}\right)}, \\
K_{\text {eff }}=\frac{K}{1+\phi_{f}\left(t-t_{0}\right)},
\end{gathered}
$$

where $\phi_{1}\left(t, t_{0}\right), \phi_{2}\left(t-t_{0}\right)$, and $\phi_{f}\left(t-t_{0}\right)$, are, respectively, the creep coefficient of concrete, timber, and mechanical connection system, $t$ and $t_{0}$ are, respectively, the final time of analysis (the end of the service life, usually 50 years) and the initial time of analysis (the time of application of the imposed load). The creep of timber and connection is provided by Eurocode 5 Part 1-1 [11] as $k_{\text {def }}$ and $\phi_{f}\left(t-t_{0}\right)$ coefficients, respectively. The creep of concrete $\phi\left(t_{\text {inf }}, t_{0}\right)$ is provided in Eurocode 2 [30] for indoor and outdoor conditions.

\section{Experimental-Analytical Comparison}

An extensive research programme on the short- and longterm behaviour of the semi-prefabricated LVL-concrete composite floor system presented in Section 4 was performed at the University of Canterbury [2]. A total of eleven T-section LVL-concrete composite floor beams built with different types, number of connections, and types of concrete with 8 and $10 \mathrm{~m}$ span were tested to destruction under 4-point bending. The outcomes of these tests are reported in [3]. This section aims to provide a comparison of the experimental results with the analytical results obtained using the elastic design formulas discussed in Section 5. Three $8 \mathrm{~m}$ span floor beams out of the eleven tested are selected for this exercise. Beam 1 had six $300 \mathrm{~mm}$ long rectangular notch connectors reinforced with coach screw (R300) along the span. Beam 2 had ten $150 \mathrm{~mm}$ long rectangular notch connectors reinforced with coach screw (R150) along the span. Beam 3 had eight pairs of modified $1 \mathrm{~mm}$ thick toothed metal plate connectors $(\mathrm{P})$ along the span. Beam 1 had $600 \mathrm{~mm}$ wide concrete flange with single LVL joist while beams 2 and 3 had $1200 \mathrm{~mm}$ wide concrete flange with double LVL joist. Figure 10 presents the experimental test results of beam 1 . Figure 10 (a) presents the total load $2 \mathrm{P}$ versus mid span deflection experimental curve in between the upper limit of a full composite beam and the lower limit of no composite beam, but very close to the upper limit indicating the high level of composite action achieved in the beam. In the same figure, the analytical curves with inclination $k_{s}$ and $k_{u}$, which represent the secant stiffness
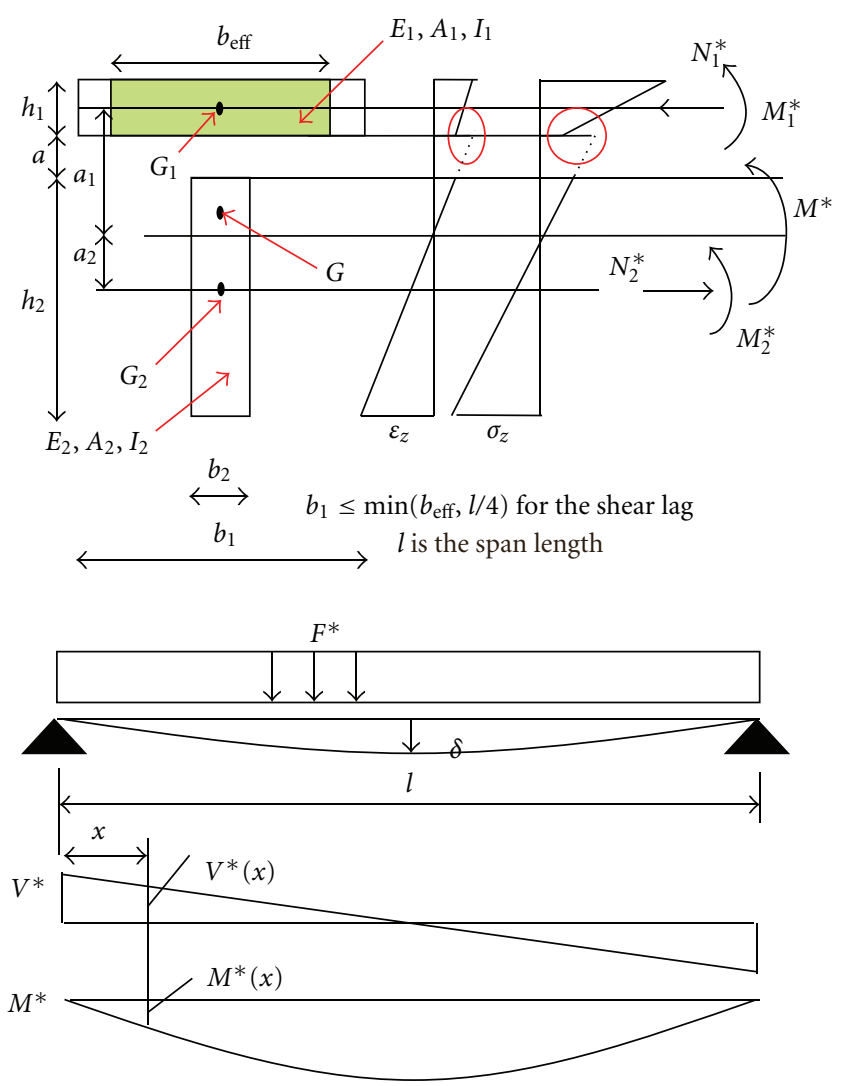

FIGURE 8: Symbols used in the elastic formulas of composite beams with flexible connection.

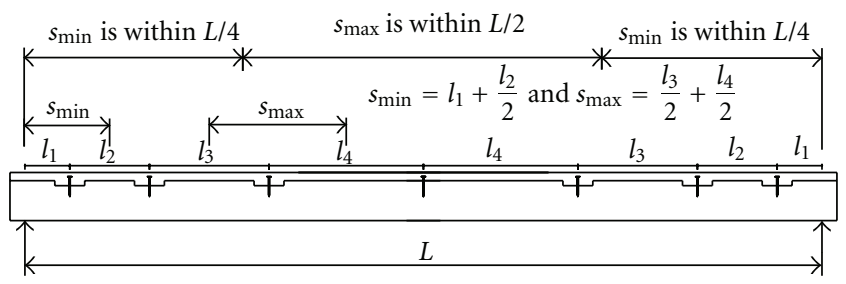

FIGURE 9: Typical TCC beam showing indicative spacing of notched connection for the definition of $s_{\min }$ and $s_{\max }$.

of the whole composite beam are used for SLS and ULS verifications, respectively, are drawn. These analytical curves are derived using the Annex B of the Eurocode 5 Part 1-1 formulas based on the experimental secant slip moduli of the connection, $K_{s}$ and $K_{u}$, at $40 \%$ and $60 \%$, respectively, of the ultimate shear load measured in push out tests [4]. Figure 10 (b) illustrates the total load $2 \mathrm{P}$ versus connection slip for all the connectors on one side of the beam with the largest slip in the second notched connector. Figure 10(c) shows the total load $2 \mathrm{P}$ versus strain measured at mid span on the top and bottom fibres of the LVL and concrete layers. Correspondingly, the stress profile of the beam section is given in Figure 10(d) at SLS, ULS, and collapse load levels, indicating that the concrete is fully in compression and the LVL is predominantly in tension. 


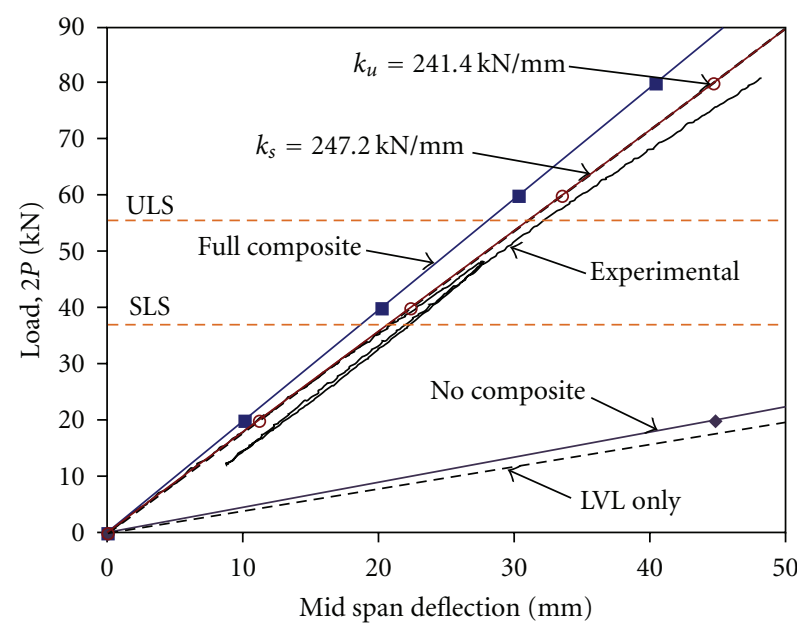

(a)

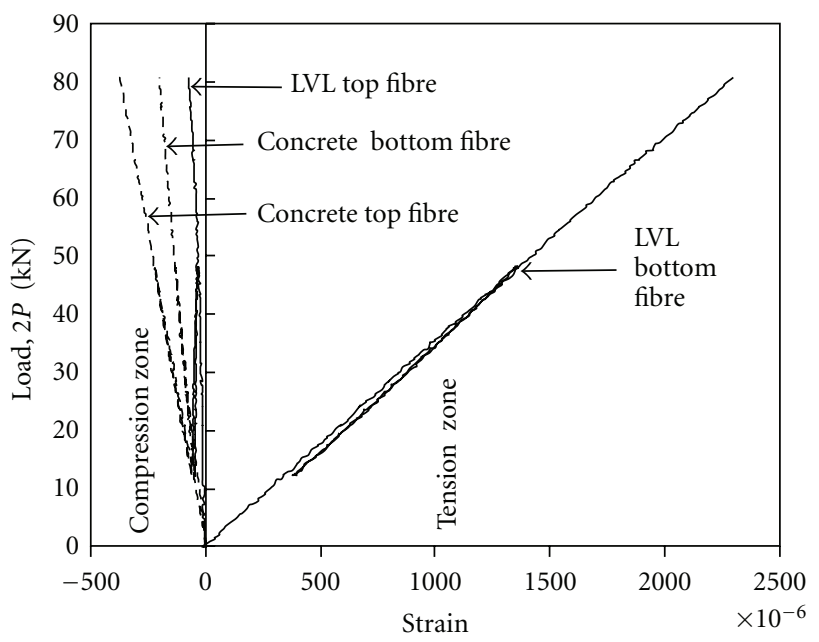

(c)

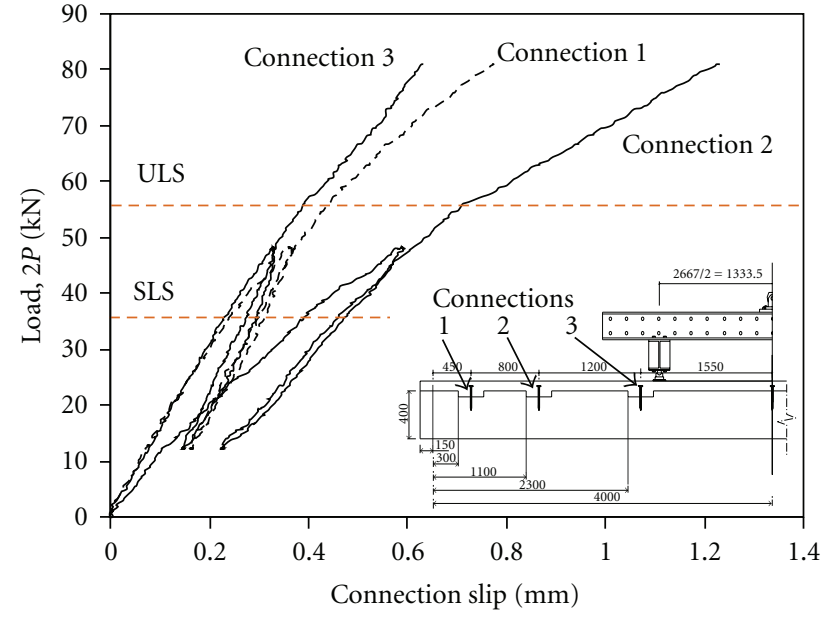

(b)

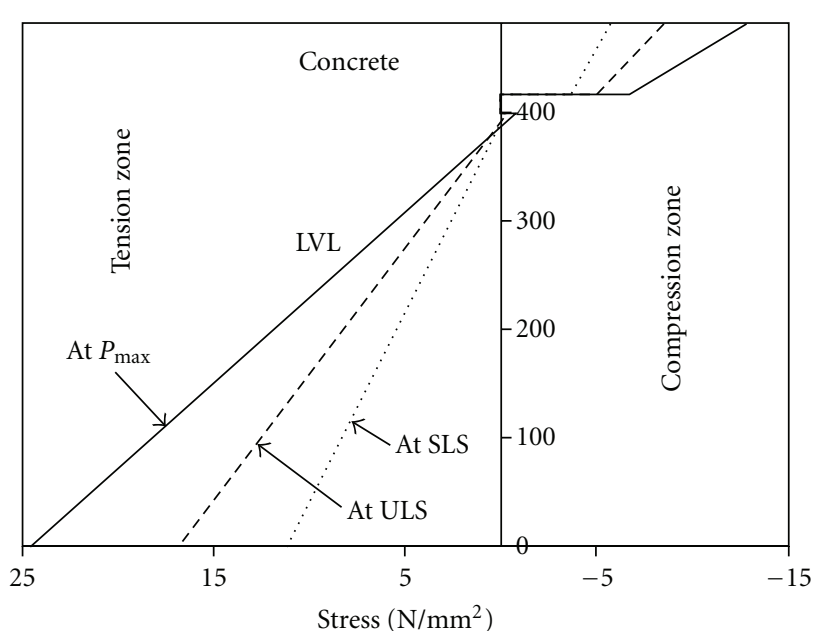

(d)

FIGURE 10: Experimental results at ULS and SLS levels for Beam 1, an $8 \mathrm{~m}$ span T-section TCC with R300-type connection system. (a) Experimental-analytical load $2 \mathrm{P}$ versus mid span deflection curve comparison. (b) Experimental load $2 \mathrm{P}$ versus connection slip curve for the notched connectors. (c) Experimental load 2P versus strain at mid span curve for LVL and concrete, bottom and top fibres. (d) Corresponding compressive and tensile stress profile in the tested T-section at SLS, ULS, and collapse $\left(P_{\max }\right)$ load.

The ULS and SLS load levels for each beam as illustrated in Figure 10 are estimated based on the experimental collapse load due to fracture in tension of LVL using the formula [28] with ULS load $2 P_{u}=\left(f_{d} / f_{m}\right) \times 2 P_{c} \times k_{\bmod }=$ $0.687\left(2 P_{c}\right)$, while the SLS load $2 P_{s}=2 P_{u} / \gamma_{Q}=0.458\left(2 P_{c}\right)$. The properties were assumed as follows: LVL design and mean strength, $f_{d}=33.85 \mathrm{~N} / \mathrm{mm}^{2}$ and $f_{m}=39.45 \mathrm{~N} / \mathrm{mm}^{2}$, respectively, both based on statistical data provided by the manufacturer; load duration modification factor, $k_{\bmod }=0.8$; partial factor for variable action, $\gamma_{Q}=1.5$.

The comparison between experimental and analytical values for beams 1,2 , and 3 in terms of mid span deflection $\left(\Delta_{V}\right)$, slip in the most stressed notched connector $\left(\Delta_{H}\right)$ and its corresponding force $\left(F_{\text {conn }}\right)$, bottom and top fibre stresses at mid span in LVL $\left(\sigma_{\mathrm{LVL}}\right)$ and concrete $\left(\sigma_{\text {conc }}\right)$ at ULS and SLS load levels are summarised in Table 1. The analytical values are predicted based on the Eurocode 5 formulas using the push-out test secant slip moduli $K_{s}$ and $K_{u}$ of the connection, respectively, for SLS and ULS levels. Referring to this comparison, the analytical predictions are below $10 \%$ difference from the experimental values for $\Delta_{V}, \Delta_{H}$, and $F_{\text {conn }}$, and for $\sigma_{\mathrm{LVL}}$ and $\sigma_{\mathrm{conc}}$, the difference is within $20 \%$, suggesting that the analytical solution is conservative.

A detailed design worked example of a simply supported LVL-concrete composite floor spanning $8 \mathrm{~m}$ for a commercial office building (Category B) in accordance with Eurocode is presented in the Appendix section of this paper. As a special requirement from the client, an imposed load $Q=4.5 \mathrm{kN} / \mathrm{m}^{2}$ is assumed. A type $\mathrm{R} 300$ notched connection reinforced with coach screw provides the composite action between concrete and LVL, similar to that of beam 1. However, the floor is made of double LVL joists as opposed to a single LVL in Beam 1. The LVL joists of type Truform produced by Carter Holt Harvey [31] are spaced 
TABLE 1: Experimental-analytical comparisons at ULS and SLS load levels for beams 1, 2, and 3 in terms of midspan deflection $\left(\Delta_{V}\right)$, slip $\left(\Delta_{H}\right)$, and shear force $\left(F_{\text {conn }}\right)$ in the most stressed notched connector, mid span bottom $\left(\sigma_{\mathrm{LVL}}\right)$ and top fibre $\left(\sigma_{\text {conc }}\right)$ stresses in LVL and concrete, respectively.

\begin{tabular}{|c|c|c|c|c|c|c|c|}
\hline \multirow{2}{*}{ Beam properties } & \multirow{2}{*}{ Quantity } & \multicolumn{3}{|c|}{ ULS } & \multicolumn{3}{|c|}{ SLS } \\
\hline & & Exp. & Analy. & Ratio of exp./analy. & Exp. & Analy. & Ratio of exp./analy. \\
\hline Beam 1 & $\Delta_{V}(\mathrm{~mm})$ & 32.2 & 32.0 & 1.01 & 21.1 & 19.7 & 1.07 \\
\hline Single LVL & $\Delta_{H}(\mathrm{~mm})$ & 0.71 & - & - & 0.31 & - & - \\
\hline R300 connection & $F_{\text {conn }}(\mathrm{kN})$ & 116 & 119 & 0.98 & 75.0 & 76.3 & 0.98 \\
\hline 6 numbers & $\sigma_{\mathrm{LVL}}\left(\mathrm{N} / \mathrm{mm}^{2}\right)$ & 15.5 & 18.6 & 0.83 & 11.2 & 12.4 & 0.90 \\
\hline $\mathrm{ULS}=55.5 \mathrm{kN}$ & $\sigma_{\text {conc }}\left(\mathrm{N} / \mathrm{mm}^{2}\right)$ & 8.55 & 10.7 & 0.80 & 5.72 & 7.15 & 0.80 \\
\hline \multicolumn{8}{|l|}{$\mathrm{SLS}=37.0 \mathrm{kN}$} \\
\hline Beam 2 & $\Delta_{V}(\mathrm{~mm})$ & 41.0 & 40.5 & 1.01 & 25.9 & 26.2 & 0.99 \\
\hline Double LVL & $\Delta_{H}(\mathrm{~mm})$ & 0.72 & - & - & 0.36 & - & - \\
\hline R150 connection & $F_{\text {conn }}(\mathrm{kN})$ & 110 & - & - & 65.0 & - & - \\
\hline 10 numbers & $\sigma_{\mathrm{LVL}}\left(\mathrm{N} / \mathrm{mm}^{2}\right)$ & 20.3 & 23.5 & 0.86 & 13.3 & 15.7 & 0.85 \\
\hline $\mathrm{ULS}=138 \mathrm{kN}$ & $\sigma_{\text {conc }}\left(\mathrm{N} / \mathrm{mm}^{2}\right)$ & 10.9 & 13.5 & 0.81 & 7.47 & 9.02 & 0.83 \\
\hline \multicolumn{8}{|l|}{ SLS $=91.9 \mathrm{kN}$} \\
\hline Beam 3 & $\Delta_{V}(\mathrm{~mm})$ & 26.3 & 25.8 & 1.02 & 16.5 & 17.0 & 0.97 \\
\hline Double LVL & $\Delta_{H}(\mathrm{~mm})$ & 0.56 & - & - & 0.21 & - & - \\
\hline P connection & $F_{\text {conn }}(\mathrm{kN})$ & 116 & 120 & 0.97 & 85.0 & 83.0 & 1.02 \\
\hline 8 numbers & $\sigma_{\mathrm{LVL}}\left(\mathrm{N} / \mathrm{mm}^{2}\right)$ & 12.3 & 15.4 & 0.80 & 8.26 & 10.3 & 0.80 \\
\hline $\mathrm{ULS}=92.2 \mathrm{kN}$ & $\sigma_{\text {conc }}\left(\mathrm{N} / \mathrm{mm}^{2}\right)$ & 9.52 & 8.92 & 1.07 & 4.93 & 5.95 & 0.83 \\
\hline $\mathrm{SLS}=61.5 \mathrm{kN}$ & & & & & & & \\
\hline
\end{tabular}

TABLE 2: Stress and deflection ratios for different ULS and SLS verifications.

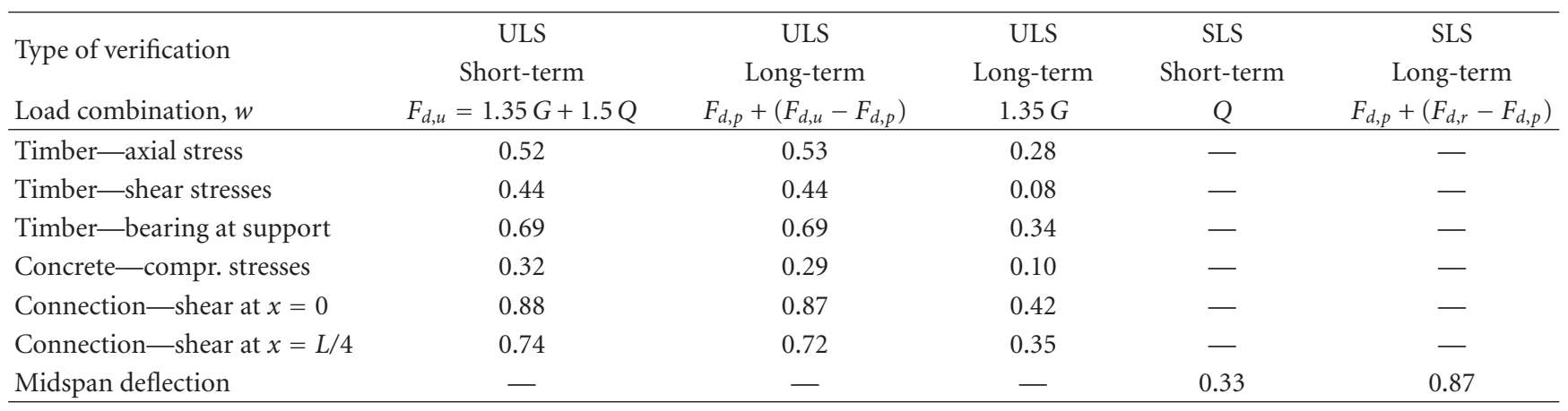

at $1200 \mathrm{~mm}$ centres with $65 \mathrm{~mm}$ thick concrete slab class C 35/45. Plywood of $17 \mathrm{~mm}$ thickness is used as a permanent formwork which separates the concrete and the LVL. The geometrical properties of the composite section are given in Figure 11 together with the stress diagrams of the section at short-term ultimate limit state being the outcomes of the design example.

The ratios between stresses, $\sigma$, and strengths, $f$, (stress ratios) for the different ULS and SLS verifications are calculated based on the solution of the detailed design worked example given in the Appendix section and are presented in Table 2. It can be observed that the most critical load condition is permanent and imposed load in the short term. Also, there are little differences between the ULS verifications in the short and long-term hence for a simplified and fast design, it is sufficient to perform only the ULS verification in the short term. In the same table, also the ratios between the deflections, $u$, and the limits are displayed, showing that SLS in the long-term is the governing design criterion together with the ULS of shear in the connection. This is often the case in timber-concrete composite structures, particularly for medium- to long- spans.

\section{Conclusions}

A design method of a novel semi-prefabricated LVL-concrete composite floor with notched connection complemented by a step- by- step worked example, carried out in accordance with the Eurocode, have been presented. The design method is based on the Annex B elastic formulas of the Eurocode 5 for composite beams with flexible connection. Due to the timedependent phenomena, both ultimate and serviceability limit states must be checked at two stages: (1) in the shortterm, just after construction, where no creep has developed yet and (2) in the long-term, at the end of the service life, where allowance for creep has to be made. The actual 


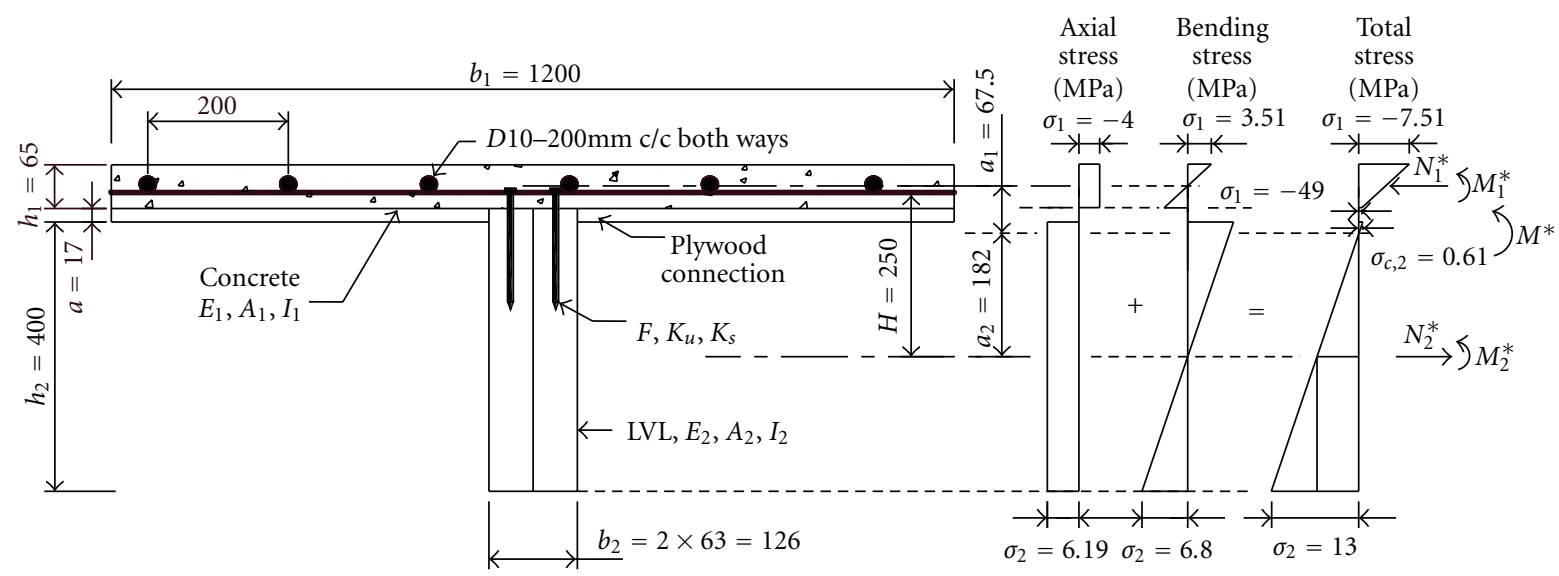

FIGURE 11: Geometrical properties and stress diagrams of LVL-concrete composite section (length unit in mm, stress unit in MPa). Stresses shown refer to verification of ultimate limit state in the short term.

nonlinear behaviour of the connection system is allowed for by using different secant slip moduli for serviceability and ultimate limit states. The creep of all component materials (concrete, timber, and connection) is considered in longterm verifications by reducing the actual elastic moduli of materials (effective modulus method). The accuracy of the proposed method is checked by comparison with experimental results, which demonstrate that the former is in general conservative.

\section{Appendix}

\section{A. TCC Design Worked Example}

\section{A.1. Design Data}

Imposed load (medium term $)=4.50 \mathrm{kN} / \mathrm{m}^{2}$

Permanent load (finishes and services) $=1.00 \mathrm{kN} / \mathrm{m}^{2}$

Superimposed permanent load (self-weight and construction load) $=2.00 \mathrm{kN} / \mathrm{m}^{2}$

Total permanent load, $G=(1+2) \times 1.2=3.60 \mathrm{kN} / \mathrm{m}$

Total imposed load, $Q=4.5 \times 1.2=5.40 \mathrm{kN} / \mathrm{m}$

ULS load combinations,

(a) uniformly distributed imposed and perm. loads, $w=1.35 G+1.5 Q=13.0 \mathrm{kN} / \mathrm{m}$;

(i) design bending moment, $M_{d}=w L^{2} / 8=$ $104 \mathrm{kN} / \mathrm{m}$;

(ii) design shear force, $V_{d}=w L / 2=52.0 \mathrm{Kn}$;

(iii) design shear force at $L / 4$ from end, $V_{L / 4}=$ $25.9 \mathrm{kN}$;

(b) uniformly distributed permanent load only, $w=1.35 G=4.86 \mathrm{kN} / \mathrm{m}$;

(i) design bending moment, $M_{d}=w L^{2} / 8=$ $38.9 \mathrm{kN} / \mathrm{m}$;

(ii) design shear force, $V_{d}=w L / 2=19.4 \mathrm{kN}$;

(iii) design shear force at $L / 4$ from end, $V_{L / 4}=$ $9.70 \mathrm{kN}$;
SLS load combinations,

(a) for short-term deflection, $Q=5.40 \mathrm{kN} / \mathrm{m}$;

(b) for long-term deflection, $G+0.3 Q=5.22 \mathrm{kN} / \mathrm{m}$;

(c) for vibration $=1.00 \mathrm{kN}$.

The connection slip moduli and strength were determined by experimental push-out test [4] for rectangular notched coach screw of $126(w) \times 50(d) \times 300(l)$ where $w$, $d$, and $l$ are the width, depth, and length in $\mathrm{mm}$, respectively. (See Figure 9 for definition of connection spacing.)

Connection slip modulus for ULS, $K_{u}=483 \mathrm{kN} / \mathrm{mm}$; Connection slip modulus for SLS, $K_{s}=495 \mathrm{kN} / \mathrm{mm}$; Characteristic strength of connection, $F_{k}=231 \mathrm{kN}$;

Maximum spacing of connection, $s_{\max }=1394 \mathrm{~mm}$;

Minimum spacing of connection, $s_{\min }=831 \mathrm{~mm}$;

Effective spacing of connection, $s_{\text {eff }}=0.75 s_{\min }+$ $0.25 s_{\max }=972 \mathrm{~mm}$;

Number of connectors along the span $=6$.

Concrete creep coefficient for long-term verifications: notional thickness, $h_{0}=2 A_{c} / u=2 \times 1200 \times 65 / 1200=$ $130 \mathrm{~mm}$, assuming a vapour flux only through the upper surface of the concrete topping during the concrete drying and aging; $\mathrm{RH}=50 \%$ (indoor conditions); age of concrete at time of loading, $t_{0}=30$ days, assuming the props are removed after 28 days and the other permanent loads are applied immediately afterwards; final creep coefficient, $\phi\left(t_{\text {inf }}, t_{0}\right)=2.25$ according to Eurocode 2 Figure 3.1 (Figure 12) [30].

Timber creep coefficient for long-term verification, $k_{\text {def }}=0.6$ according to Eurocode 5 Table 3.2 [11] for LVL under Service Class 1, since the timber-concrete composite floor is in heated, indoor environmental conditions (relative humidity of the environment only exceeding $65 \%$ for a few weeks per year, with average timber moisture content smaller than $12 \%)$. 


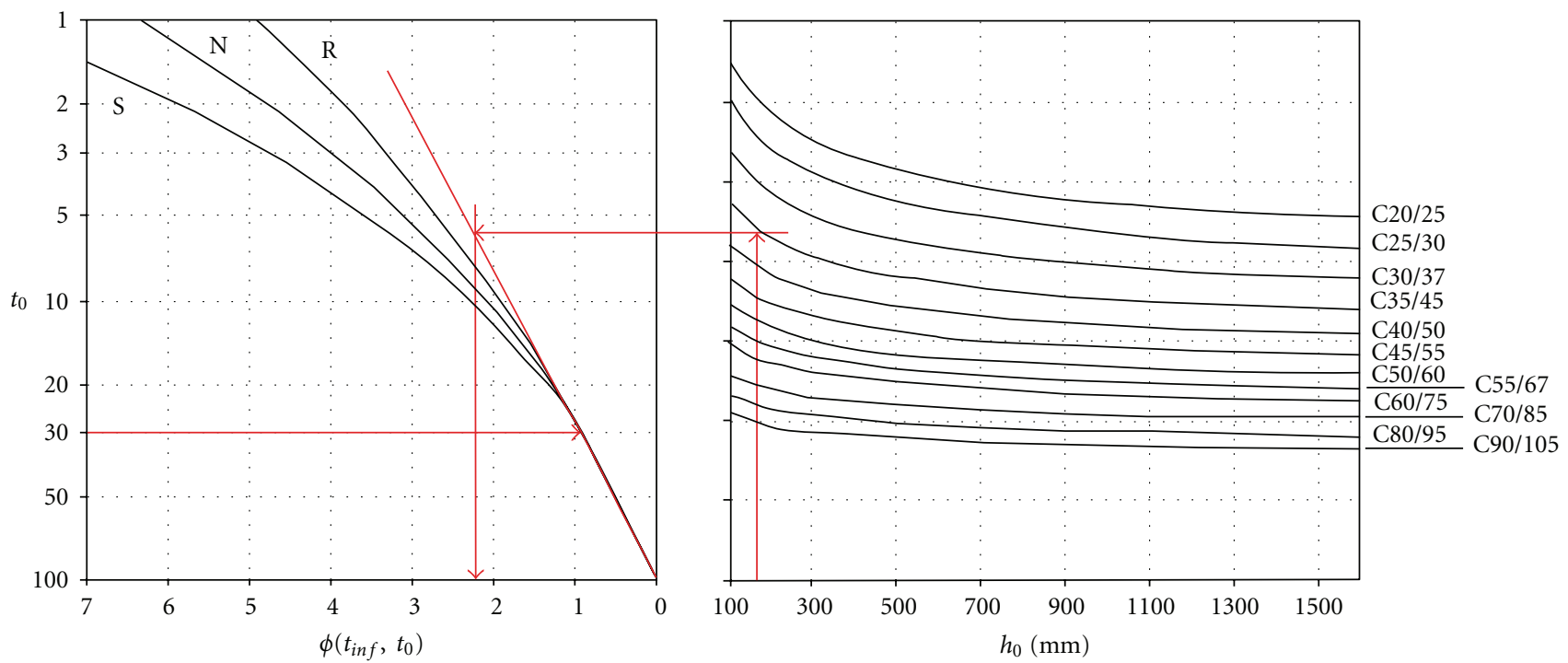

Inside conditions- $\mathrm{RH}=50 \%$

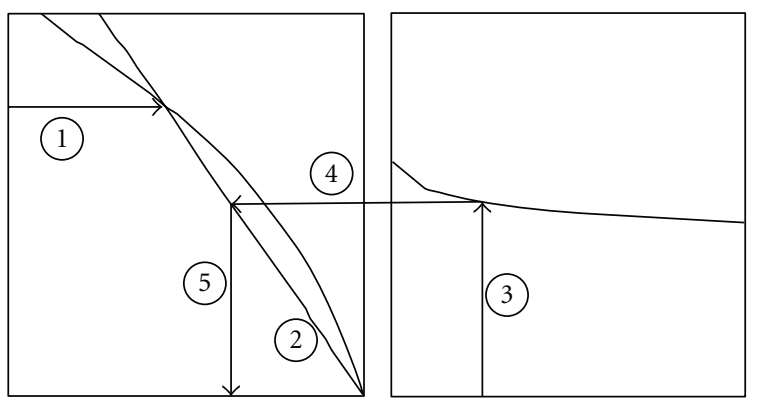

Classes R, $\mathrm{N}$ and $\mathrm{S}$ :

$=0.2$ for cement of strength classes CEM $42.5 \mathrm{R}$,

CEM 53.5 N and CEM 53.5 R (class R)

$=0.35$ for cement strength classes CEM 32.5 R,

CEM $42.5 \mathrm{~N}$ (class $\mathrm{N}$ )

$=0.38$ for cement strength classes CEM

$32.5 \mathrm{~N}$ (class S)

FIGURE 12: Evaluation of the creep coefficient of concrete according to Figure 3.1 of Eurocode 2 [30].

Rectangular notched connection creep coefficient, $\phi_{f}(t-$ $\left.t_{0}\right)=1.57$, obtained from experimental long-term push-out test [32].

Timber Strength Capacity for Truform LVL [33]

(a) For uniformly distributed imposed and permanent load, $w=1.35 G+1.5 Q=13.0 \mathrm{kN} / \mathrm{m}$

Young's modulus of LVL, $E_{2}=10700 \mathrm{MPa}$;

Timber design tensile strength, $f_{t, 0, d}=k_{\bmod } \times f_{t, 0, k} /$ $\gamma_{m}=0.8 \times 30 / 1.2=20.0 \mathrm{~N} / \mathrm{mm}^{2}$;

Timber design bending strength, $f_{m, d}=k_{\bmod } \times f_{m, k} /$ $\gamma_{m}=0.8 \times 48 / 1.2=32.0 \mathrm{~N} / \mathrm{mm}^{2}$;

Timber shear design strength, $f_{v, d}=k_{\bmod } \times f_{v, k} / \gamma_{m}=$ $0.8 \times 5.3 / 1.2=3.53 \mathrm{~N} / \mathrm{mm}^{2}$;

Timber compression perpendicular to grain design strength, $f_{c, 90, d}=k_{\bmod } \times f_{c, 90, k} / \gamma_{m}=0.8 \times 12 / 1.2=$ $8.00 \mathrm{~N} / \mathrm{mm}^{2}$;

Timber compression parallel to grain design strength, $f_{c, 0, d}=k_{\bmod } \times f_{c, 0, k} / \gamma_{m}=0.8 \times 45 / 1.2=30.0 \mathrm{~N} / \mathrm{mm}^{2}$,

where $\gamma_{m}=1.2$ is partial factor for material properties LVL; and $k_{\bmod }=0.8$ is modification factor for medium term load duration and moisture content in Service Class 1 (Eurocode 5 Part 1-1, Table 3.1) [11].

(b) For uniformly distributed permanent load only, $w=$ $1.35 G=4.86 \mathrm{kN} / \mathrm{m}$ :

Young's modulus of LVL, $E_{2}=10700 \mathrm{MPa}$

Timber design tensile strength, $f_{t, 0, d}=k_{\bmod } \times f_{t, 0, k} /$ $\gamma_{m}=0.6 \times 30 / 1.2=15.0 \mathrm{~N} / \mathrm{mm}^{2}$;

Timber design bending strength, $f_{m, d}=k_{\bmod } \times f_{m, k} /$ $\gamma_{m}=0.6 \times 48 / 1.2=24.0 \mathrm{~N} / \mathrm{mm}^{2}$;

Timber shear design strength, $f_{v, d}=k_{\bmod } \times f_{v, k} / \gamma_{m}=$ $0.6 \times 5.3 / 1.2=7.36 \mathrm{~N} / \mathrm{mm}^{2}$;

Timber compression perpendicular to grain design strength, $f_{c, 90, d}=k_{\bmod } \times f_{c, 0, k} / \gamma_{m}=0.6 \times 12 /$ 1.26.00 N/mm

Timber compression parallel to grain design strength, $f_{c, 0, d}=k_{\bmod } \times f_{c, 0, k} / \gamma_{m}=0.6 \times 45 / 1.2=22.5 \mathrm{~N} / \mathrm{mm}^{2}$,

where $\gamma_{m}=1.2$ is partial factor for material properties LVL and $k_{\bmod }=0.6$ is modification factor for permanent load duration and moisture content in Service Class 1 (Eurocode 5, Part 1-1, Table 3.1) [11].

Concrete Strength Capacity for Class C 35/45 
Young's modulus of concrete, $E_{1}=34000 \mathrm{MPa}$;

Concrete design compressive strength, $f_{c d}=f_{c k} / \gamma_{c}=$ $35 / 1.5=23.3 \mathrm{~N} / \mathrm{mm}^{2}$;

Concrete design tensile strength, $f_{c t d}=f_{c t k} / \gamma_{c}=$ $2.2 / 1.5=1.47 \mathrm{~N} / \mathrm{mm}^{2}$,

where $\gamma_{c}$ is partial factor for concrete at ultimate limit state (Eurocode, 2 Part 1-1, Table 2.1).

Effective width of concrete topping, $b_{\text {eff }}=b_{2}+b_{\text {eff, } 1}+$ $b_{\text {eff }, 2} \leq b_{1}$ with $b_{\mathrm{eff}, i}=0.2\left(b_{1}-b_{2}\right) / 2+0.1 L \leq\left(b_{1}-\right.$ $\left.b_{2}\right) / 2 b_{\text {eff, } 1}=b_{\text {eff } 2}=0.2 \times(1200-126) / 2+0.1 \times 8000=$ $907.4 \mathrm{~mm}>\left(b_{1}-b_{2}\right) / 2537 \mathrm{~mm}$; therefore, $b_{\text {eff, } 1}=b_{\text {eff }, 2}=$ $537 \mathrm{~mm} ; b_{\text {eff }}=126+537+537=1200 \mathrm{~mm}=b_{1}$ (Eurocode 5, Part 2 Clause 5.3(3) [10] and Eurocode 2, Part 1-1, Clause 5.3.2.1) [30].

Connection Strength Capacity for Rectangular Notch Connectors

(a) For uniformly distributed imposed and permanent load, $w=1.35 G+1.5 Q=13.0 \mathrm{kN} / \mathrm{m}$

Characteristic strength of connection, $F_{k}=231 \mathrm{kN}$;

Design strength of connection, $F_{d}=k_{\bmod } \times F_{k} / \gamma_{m}=$ $0.8 \times 231 / 1.25=148 \mathrm{kN}$,

where $\gamma_{m}=1.25$ is partial factor for material properties TCC and $k_{\text {mod }}=0.8$ is modification factor for medium-term load duration and moisture content in Service Class 1 (Eurocode 5, Part 1-1, Table 3.1) [11].

(b) For uniformly distributed permanent load only, $w=$ $1.35 G=4.86 \mathrm{kN} / \mathrm{m}$

Characteristic strength of connection, $F_{k}=231 \mathrm{kN}$,

Design strength of connection, $F_{d}=k_{\bmod } \times F_{k} / \gamma_{m}=$ $0.6 \times 231 / 1.25=111 \mathrm{kN}$,

where $\gamma_{m}=1.25$ is partial factor for material properties TCC and $k_{\bmod }=0.6$ is modification factor for permanent load duration and moisture content in Service Class 1 (Eurocode 5, Part 1-1, Table 3.1) [11].

\section{A.2. Solution}

Verifications performed in this worked example are

(1) Ultimate limit state in the short-term, for the load condition with permanent and imposed loads,

(2) Serviceability limit state in the short term,

(3) Ultimate limit state in the long term, for the load condition with permanent and imposed loads (3a) and for the load condition with permanent loads only (3b),

(4) Serviceability limit state in the long term.

(1) Verifications for Ultimate Limit State in the Short Term

This verification is carried out for the load condition with uniformly distributed imposed and permanent loads; $w=$ $1.35 G+1.5 Q=13.0 \mathrm{kN} / \mathrm{m}$.
Bending Stiffness Properties for Ultimate Limit State ShortTerm Verifications are as follows.

Concrete gamma coefficient,

$$
\begin{aligned}
\gamma_{1} & =\frac{1}{1+\left(\pi^{2} E_{1} A_{1} s_{\mathrm{ef}} / K_{u} l^{2}\right)} \\
& =\frac{1}{1+\left(\pi^{2}(34000)(65 \times 1200) 971.8 / 482860(8000)^{2}\right)} \\
& =0.55 ;
\end{aligned}
$$

$a_{1}$ distance,

$$
\begin{aligned}
a_{1} & =\frac{E_{2} A_{2} H}{\gamma_{1} E_{1} A_{1}+\gamma_{2} E_{2} A_{2}} \\
& =\frac{10700(126 \times 400)(250)}{0.55(34000)(65 \times 1200)+1(10700)(126 \times 400)} \\
& =67.5 \mathrm{~mm},
\end{aligned}
$$

where $H=h_{1} / 2+a+h_{2} / 2=65 / 2+17+400 / 2=250 \mathrm{~mm}$; $a_{2}$ distance, $a_{2}=\gamma_{1} E_{1} A_{1} H /\left(\gamma_{1} E_{1} A_{1}+E_{2} A_{2}\right)$ or $a_{2}=H-a_{1}=$ $250-67.5=182 \mathrm{~mm}$;

Effective flexural stiffness,

$$
\begin{aligned}
(E I)_{\mathrm{ef}}= & E_{1} I_{1}+E_{2} I_{2}+\gamma_{1} E_{1} A_{1} a_{1}^{2}+E_{2} A_{2} a_{2}^{2} \\
= & 34000\left(2.75 \times 10^{7}\right)+10700(6.72 \times 108) \\
& +0.55(34000)(78000)(67.5)^{2} \\
& +(10700)(50400)(182)^{2}=3.26 \times 10^{13} \mathrm{~N} / \mathrm{mm}^{2}
\end{aligned}
$$

where $I_{1}=b_{1} h_{1}^{3} / 12$ and $I_{2}=b_{2} h_{2}^{3} / 12$.

Timber Strength Demand and Inequalities

Timber axial stress due to axial force,

$$
\begin{aligned}
\sigma_{2}(x) & =\frac{E_{2} a_{2} M(x)}{(E I)_{\mathrm{ef}}} \\
& =\frac{(10700)(182)\left(104 \times 10^{6}\right)}{3.26 \times 10^{13}} \\
& =6.19 \mathrm{~N} / \mathrm{mm}^{2} .
\end{aligned}
$$

Timber axial stress due to bending moment,

$$
\begin{aligned}
\sigma_{m, 2}(x) & =\frac{1}{2} \cdot \frac{E_{2} h_{2} M(x)}{(E I)_{\mathrm{ef}}} \\
& =0.5(10700) \frac{(400)(104 \times 106)}{3.26 \times 10^{13}} \\
& =6.80 \mathrm{~N} / \mathrm{mm}^{2} .
\end{aligned}
$$


Combined bending and tension ratio, $\sigma_{2} / f_{t, 0, d}+\sigma_{m, 2} / f_{m, d}<=1$

$$
\begin{aligned}
\frac{\sigma_{2}}{f_{t, 0, d}}+\frac{\sigma_{m, 2}}{f_{m, d}} & =6.19 / 20+6.80 / 32 \\
& =0.52<1 \therefore \text { satisfactory. }
\end{aligned}
$$

Timber shear stress, with the simplified and conservative assumption that only the timber part resists shear:

$$
\begin{array}{r}
\tau_{d, \max }=1.5\left(\frac{V_{d}}{A_{2}}\right)=1.5\left(\frac{51.8 \times 10^{3}}{50400}\right) \\
=1.54 \mathrm{~N} / \mathrm{mm}^{2}<f_{v, d}=3.53 \mathrm{~N} / \mathrm{mm}^{2} \\
\therefore \text { satisfactory. }
\end{array}
$$

Bearing of timber at support with a bearing length $l_{b}$ of $75 \mathrm{~mm}$,

$$
\begin{aligned}
& \sigma_{d, \max }= \frac{V_{d}}{l_{b} b_{2}}=\frac{51.8 \times 10^{3}}{75 \times 126} \\
&=5.48 \mathrm{~N} / \mathrm{mm}^{2}<f_{c, 90, d}=8.00 \mathrm{~N} / \mathrm{mm}^{2} \\
& \therefore \text { satisfactory. }
\end{aligned}
$$

\section{Concrete Strength Demand and Inequalities}

Concrete axial stress due to axial force,

$$
\begin{aligned}
\sigma_{1}(x) & =\frac{\gamma_{1} E_{1} a_{1} M(x)}{(E I)_{\mathrm{ef}}} \\
& =\frac{0.55(34000)(67.5)\left(104 \times 10^{6}\right)}{3.26 \times 10^{13}}=4.00 \mathrm{~N} / \mathrm{mm}^{2} .
\end{aligned}
$$

Concrete axial stress due to bending moment

$$
\begin{aligned}
\sigma_{m, 1}(x) & =\frac{1}{2} \cdot \frac{E_{1} h_{1} M(x)}{(E I)_{\mathrm{ef}}} \\
& =\frac{0.5(34000)(65)\left(104 \times 10^{6}\right)}{3.26 \times 10^{13}}=3.51 \mathrm{~N} / \mathrm{mm}^{2} .
\end{aligned}
$$

Concrete total upper fibre stress

$$
\begin{aligned}
\sigma_{c, \text { tot }} & =\left|-\sigma_{1}-\sigma_{m, 1}\right| \\
& =|-4.00-3.51|=7.51 \mathrm{~N} / \mathrm{mm}^{2}<f_{c d} \\
& =23.3 \mathrm{~N} / \mathrm{mm}^{2} \therefore \text { satisfactory. }
\end{aligned}
$$

Concrete total lower fibre stress

$$
\begin{aligned}
\sigma_{t, \mathrm{tot}} & =-\sigma_{1}+\sigma_{m, 1} \\
& =-4.00+3.51=-0.49 \mathrm{~N} / \mathrm{mm}^{2}(\text { compression }) \\
& <f_{c t d}=1.47 \mathrm{~N} / \mathrm{mm}^{2} \therefore \text { satisfactory. }
\end{aligned}
$$

Connection Strength Demand and Inequalities
Shear force in connection at maximum shear,

$$
\begin{aligned}
F_{(x=0)} & =\frac{\gamma_{1} E_{1} A_{1} a_{1} s_{\min }}{(E I)_{\mathrm{ef}}} \cdot V_{\max } \\
& =\frac{0.55(34000)(78000)(67.5)(831)}{3.26 \times 10^{13}} \times 51.8 \times 10^{3} \\
& =130 \mathrm{kN}<F_{d}=148 \mathrm{kN} \therefore \text { satisfactory. }
\end{aligned}
$$

Shear force in connection at $L / 4$,

$$
\begin{aligned}
F_{(x=L / 4)} & =\frac{\gamma_{1} E_{1} A_{1} a_{1} s_{\max }}{(E I)_{\mathrm{ef}}} \cdot V_{L / 4} \\
& =\frac{0.55(34000)(78000)(67.5)(1394)}{3.26 \times 10^{13}} \times 25.9 \times 10^{3} \\
& =109 \mathrm{kN}<F_{d}=148 \mathrm{kN} \therefore \text { satisfactory. }
\end{aligned}
$$

(2) Verification for Serviceability Limit State in the Short Term

This verification is carried out for the uniformly distributed imposed load $Q$ (deflection control) and for $P=$ $1 \mathrm{kN}$ concentrated load (simplified vibrations control).

Bending Stiffness Properties for Serviceability Limit State Short-Term Verifications are as follows

Concrete gamma coefficient

$$
\begin{aligned}
\gamma_{1} & =\frac{1}{1+\left(\pi^{2} E_{1} A_{1} s_{\mathrm{ef}} / K_{s}{ }^{2}\right)} \\
& =\frac{1}{1+\left(\pi^{2}(34000)(65 \times 1200) 971.8 / 494460(8000)^{2}\right)} \\
& =0.56 ;
\end{aligned}
$$

$a_{1}$ distance,

$$
\begin{aligned}
a_{1} & =\frac{\gamma_{2} E_{2} A_{2} H}{\gamma_{1} E_{1} A_{1}+\gamma_{2} E_{2} A_{2}} \\
& =\frac{10700(126 \times 400)(250)}{0.56(34000)(65 \times 1200)+1(10700)(126 \times 400)} \\
& =66.9 \mathrm{~mm} ;
\end{aligned}
$$

$a_{2}$ distance,

$$
\begin{aligned}
a_{2} & =\frac{\gamma_{1} E_{1} A_{1} H}{\gamma_{1} E_{1} A_{1}+\gamma_{2} E_{2} A_{2}} \quad \text { or } a_{2}=H-a_{1} \\
& =250-66.9=183 \mathrm{~mm} ;
\end{aligned}
$$


Effective flexural stiffness

$$
\begin{aligned}
(E I)_{\mathrm{ef}}= & E_{1} I_{1}+E_{2} I_{2}+\gamma_{1} E_{1} A_{1} a_{1}^{2}+\gamma_{2} E_{2} A_{2} a_{2}^{2} \\
= & 34000\left(2.75 \times 10^{7}\right)+10700\left(6.72 \times 10^{8}\right) \\
& +0.56(34000)(78000)(66.9)^{2} \\
& +(10700)(50400)(183)^{2} \\
= & 3.27 \times 10^{13} \mathrm{Nmm}^{2} .
\end{aligned}
$$

\section{Deflection Inequalities}

Deflection under $1 \mathrm{kN}$ load for vibration,

$$
\begin{aligned}
u_{\text {vibration }} & =\frac{P l^{3}}{48(E I)_{\mathrm{ef}}}=\frac{1000(8000)^{3}}{48\left(3.27 \times 10^{13}\right)} \\
& =0.33 \mathrm{~mm} \\
& <\text { allowable deflection for vibration of } 1 \text { to } 2 \mathrm{~mm}
\end{aligned}
$$$$
\therefore \text { satisfactory. }
$$

Remark 1. The deflection under $1 \mathrm{kN}$ load also satisfies the Canadian relationship (Figure 13) between span and acceptable deflection under $1 \mathrm{kN}$ point load: $u_{\text {vibration }}=$ $0.33 \mathrm{~mm}<2.55 / L^{0.63}=2.55 / 8^{0.63}=0.69 \mathrm{~mm}[34]$.

Instantaneous deflection just after the application of live load,

$$
\begin{aligned}
u_{\text {instant }} & =\frac{5 Q l^{4}}{384\left(E I_{\text {eff }}\right)}=\frac{5(5.4)(8000)^{4}}{384\left(3.27 \times 10^{13}\right)} \\
& =8.81 \mathrm{~mm}<u_{\text {allow }}=\operatorname{span} / 300=26.7 \mathrm{~mm}
\end{aligned}
$$$$
\therefore \text { satisfactory. }
$$

(3) Verification for Ultimate Limit State in the Long-Term

This verification is carried out for two load conditions:

(3a) permanent and imposed loads: $w=1.35 G+1.5 Q=$ $13.0 \mathrm{kN} / \mathrm{m}$,

(3b) only permanent load: $w=1.35 G=4.86 \mathrm{kN} / \mathrm{m}$.

(3a) Verification for Ultimate Limit State in the Long-Term due to Permanent and Imposed Loads

Since a redistribution of forces takes place in the composite beam due to the different creep behaviour of the component materials (timber, concrete, and connection), the characteristic load condition $F_{d, u}$ is split into the sum of (i) the quasi permanent $F_{d, p}$ load condition, which causes creep deformation in the materials, and (ii) the difference $F_{d, u}-F_{d, p}$, which only causes instantaneous effects. The stresses are calculated separately under $F_{d, p}$ and $F_{d, u}-F_{d, p}$, and then superimposed.

Fictitious effective moduli accounting for time-dependent effects at final time, $t$, of analysis (the end of the service life, usually 50 years) are the following:

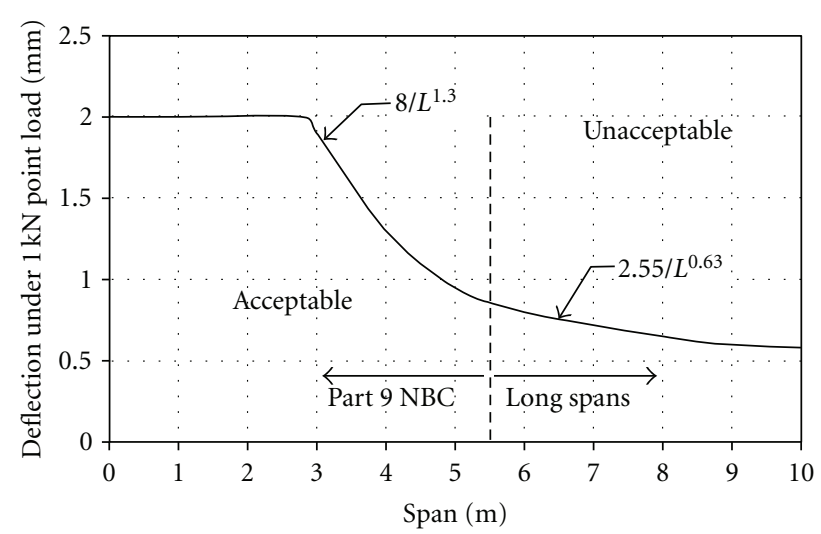

FIgURE 13: Canadian relationship between span and acceptable deflection under $1 \mathrm{kN}$ point load for control of vibrations [34].

Effective modulus for concrete,

$$
\begin{aligned}
E_{1, \text { eff }} & =\frac{E_{1}}{1+\phi\left(t_{\text {inf }}, t_{0}\right)} \\
& =\frac{34000}{1+2.25}=10462 \mathrm{~N} / \mathrm{mm}^{2},
\end{aligned}
$$

Effective modulus for timber,

$$
\begin{aligned}
E_{2, \text { eff }} & =\frac{E_{2}}{1+k_{\text {def }}} \\
& =\frac{10700}{1+0.6}=6688 \mathrm{~N} / \mathrm{mm}^{2},
\end{aligned}
$$

Effective slip modulus for connection at ULS,

$$
K_{u, \text { eff }}=\frac{K_{u}}{1+\phi_{f}\left(t-t_{0}\right)}=\frac{482857}{1+1.57}=187955 \mathrm{~N} / \mathrm{mm}^{2},
$$

Effective slip modulus for connection at SLS,

$$
\begin{aligned}
K_{s, \text { eff }} & =\frac{K_{s}}{1+\phi_{f}\left(t-t_{0}\right)} \\
& =\frac{494466}{1+1.57}=192474 \frac{\mathrm{N}}{\mathrm{mm}^{2}},
\end{aligned}
$$

(i) Solution for quasi-permanent load combination, $F_{d, p}$ (throughout the service life of the structure), where: $F_{d, p}=$ $G+0.3 Q=3.6+(0.3 \times 5.4)=5.22 \mathrm{kN} / \mathrm{m}$.

Design bending moment,

$$
M_{d}=\frac{F_{d, p} p^{2}}{8}=\frac{(5.22)(8)^{2}}{8}=41.8 \mathrm{kNm} .
$$

Design maximum shear force,

$$
V_{d}=\frac{F_{d, p} l}{2}=\frac{(5.22) 8}{2}=20.9 \mathrm{kN} .
$$

Design shear force at $L / 4$,

$$
V_{L / 4}=\frac{V_{d}}{2}=\frac{20.9}{2}=10.4 \mathrm{kN} .
$$


Bending Stiffness Properties for Ultimate Limit State Long Term Verifications throughout the Service Life of the Structure:

Concrete gamma coefficient,

$$
\begin{aligned}
\gamma_{1} & =\frac{1}{1+\left(\pi^{2} E_{1, \mathrm{eff}} A_{1} s_{\mathrm{ef}} / K_{s, \mathrm{eff}} l^{2}\right)} \\
& =\frac{1}{1+\left(\pi^{2}(10462)(65 \times 1200) 972 / 192474(8000)^{2}\right)} \\
& =0.61 ;
\end{aligned}
$$

$a_{1}$ distance,

$$
\begin{aligned}
a_{1} & =\frac{E_{2, \mathrm{eff}} A_{2} H}{\gamma_{1} E_{1, \mathrm{eff}} A_{1}+E_{2, \mathrm{eff}} A_{2}} \\
& =\frac{6688(126 \times 400)(250)}{0.61(10462)(65 \times 1200)+(6688)(126 \times 400)} \\
& =101 \mathrm{~mm} ;
\end{aligned}
$$

$a_{2}$ distance,

$$
\begin{aligned}
& a_{2}=\frac{\gamma_{1} E_{1, \mathrm{eff}} A_{1} H}{\gamma_{1} E_{1, \mathrm{eff}} A_{1}+E_{2, \mathrm{eff}} A_{2}} \text { or } \\
& a_{2}=H-a_{1}=250-101=149 \mathrm{~mm} ;
\end{aligned}
$$

Effective flexural stiffness,

$$
\begin{aligned}
(E I)_{\mathrm{ef}}= & E_{1, \mathrm{eff}} I_{1}+E_{2, \mathrm{eff}} I_{2}+\gamma_{1} E_{1, \mathrm{eff}} A_{1} a_{1}^{2}+E_{2, \mathrm{eff}} A_{2} a_{2}^{2} \\
= & 10462\left(2.75 \times 10^{7}\right)+6688\left(6.72 \times 10^{8}\right) \\
& +0.61(10462)(78000)(104)^{2} \\
& +(6688)(50400)(146)^{2} \\
= & 1.73 \times 10^{13} \mathrm{Nmm}^{2} .
\end{aligned}
$$

(ii) Solution for the difference between ultimate and quasipermanent load combinations, $F_{d, u}-F_{d, p}$ (at the end of service life), where

$$
\begin{aligned}
F_{d, u}-F_{d, p} & =(1.35 G+1.5 Q)-(G+0.3 Q)=0.35 G+1.2 Q \\
& =(0.35 \times 3.6)+(1.2 \times 5.4)=7.74 \mathrm{kN} / \mathrm{m}
\end{aligned}
$$

Design bending moment,

$$
M_{d}=\frac{\left(F_{d, u}-F_{d, p}\right) l^{2}}{8}=\frac{(7.74)(8)^{2}}{8}=61.9 \mathrm{kNm} .
$$

Design maximum shear force,

$$
V_{d}=\frac{\left(F_{d, u}-F_{d, p}\right) l}{2}=\frac{(5.76) 8}{2}=31.0 \mathrm{kN} .
$$

Design shear force at $L / 4$,

$$
V_{L / 4}=\frac{V_{d}}{2}=\frac{31}{2}=15.5 \mathrm{kN}
$$

In this solution, the bending stiffness properties similar to the ultimate limit state short-term is used because the load combinations $F_{d, u}-F_{d, p}$ is applied instantaneously at the end of service life and does not cause creep redistribution.

Bending Stiffness Properties for Ultimate Limit State LongTerm Verifications at the End of Service Life (Similar to the Bending Stiffness Properties for Ultimate Limit State ShortTerm):

Effective flexural stiffness,

$$
\begin{aligned}
(E I)_{\mathrm{ef}} & =E_{1} I_{1}+E_{2} I_{2}+\gamma_{1} E_{1} A_{1} a_{1}^{2}+E_{2} A_{2} a_{2}^{2} \\
& =3.26 \times 1013 \mathrm{~N} / \mathrm{mm}^{2} .
\end{aligned}
$$

Timber Strength Demand and Inequalitie

Timber axial stress due to axial force for $F_{d, p}$ load combination,

$$
\begin{aligned}
\sigma_{2}(x) & =E_{2, \text { eff }} \frac{a_{2} M(x)}{(E I)_{\mathrm{ef}}}=\frac{(6688)(149)\left(41.8 \times 10^{6}\right)}{1.73 \times 10^{13}} \\
& =2.40 \mathrm{~N} / \mathrm{mm}^{2} .
\end{aligned}
$$

Timber axial stress due to axial force for $F_{d, u}-F_{d, p}$ load combination,

$$
\begin{aligned}
\sigma_{2}(x) & =\frac{E_{2} a_{2} M(x)}{(E I)_{\mathrm{ef}}}=\frac{(10700)(182) 61.9 \times 10^{6}}{3.26 \times 10^{13}} \\
& =3.70 \mathrm{~N} / \mathrm{mm}^{2} .
\end{aligned}
$$

Total timber axial stress due to axial force (superposition), $\sigma_{2, \text { tot }}=2.40+3.70=6.10 \mathrm{~N} / \mathrm{mm}^{2}$.

Timber axial stress due to bending moment for $F_{d, p}$ load combination,

$$
\begin{aligned}
\sigma_{m, 2}(x) & =\frac{1}{2} \cdot \frac{E_{2, \mathrm{eff}} h_{2} M(x)}{(E I)_{\mathrm{ef}}} \\
& =\frac{0.5(6688)(400)\left(41.8 \times 10^{6}\right)}{1.73 \times 10^{13}}=3.23 \mathrm{~N} / \mathrm{mm}^{2} .
\end{aligned}
$$

Timber axial stress due to bending moment for $F_{d, u}-F_{d, p}$ load combination,

$$
\begin{aligned}
\sigma_{m, 2}(x) & =\frac{1}{2} \cdot \frac{E_{2} h_{2} M(x)}{(E I)_{\mathrm{ef}}} \\
& =\frac{0.5(10700)(400)\left(61.9 \times 10^{6}\right)}{3.26 \times 10^{13}}=4.06 \mathrm{~N} / \mathrm{mm}^{2} .
\end{aligned}
$$

Total timber axial stress due to bending moment (superposition), $\sigma_{m, 2 \text {,tot }}=3.23+4.06=7.29 \mathrm{~N} / \mathrm{mm}^{2}$.

Combined bending and tension ratio, $\sigma_{2, \text { tot }} / f_{t, 0, d}+\sigma_{m, 2, \text { tot }} /$ $f_{m, d}<=1 \sigma_{2, \text { tot }} / f_{t, 0, d}+\sigma_{m, 2, \text { tot }} / f_{m, d}=6.10 / 20+7.29 / 32=$ $0.53<1 \therefore$ satisfactory.

Timber shear stress for $F_{d, p}$ load combination,

$$
\begin{aligned}
\tau_{d, \max } & =1.5 \frac{V_{d}}{A_{2}}=1.5\left(\frac{20.9 \times 10^{3}}{50400}\right) \\
& =0.62 \mathrm{~N} / \mathrm{mm}^{2} .
\end{aligned}
$$


Timber shear stress for $F_{d, u}--F_{d, p}$ load combination,

$$
\begin{aligned}
\tau_{d, \max } & =1.5 \frac{V_{d}}{A_{2}}=1.5\left(\frac{31.0 \times 10^{3}}{50400}\right) \\
& =0.92 \mathrm{~N} / \mathrm{mm}^{2} .
\end{aligned}
$$

Total timber shear stress (superposition), $\tau_{\max \text {,tot }}=0.62+$ $0.92=1.54 \mathrm{~N} / \mathrm{mm}^{2}<f_{v, d}=3.53 \mathrm{~N} / \mathrm{mm}^{2} \therefore$ satisfactory.

Bearing of timber at support with a bearing length $l_{b}$ of $75 \mathrm{~mm}$ for $F_{d, p}$ load combination,

$$
\sigma_{d, \max }=\frac{V_{d}}{l_{b} b_{2}}=\frac{20.9 \times 10^{3}}{75 \times 126}=2.21 \mathrm{~N} / \mathrm{mm}^{2} .
$$

Bearing of timber at support with a bearing length $l_{b}$ of $75 \mathrm{~mm}$ for $F_{d, u}-F_{d, p}$ load combination,

$$
\sigma_{d, \max }=\frac{V_{d}}{l_{b} b_{2}}=\frac{31.0 \times 10^{3}}{75 \times 126}=3.28 \mathrm{~N} / \mathrm{mm}^{2} .
$$

Total bearing of timber at support (superposition), $\sigma_{d \text {,tot }}=$ $2.21+3.28=5.49 \mathrm{~N} / \mathrm{mm}^{2}<F_{c, 90, d}=8.00 \mathrm{~N} / \mathrm{mm}^{2} \therefore$ satisfactory.

\section{Concrete Strength Demand and Inequalities}

Concrete axial stress due to axial force for $F_{d, p}$ load combination,

$$
\begin{aligned}
\sigma_{1}(x) & =\frac{\gamma_{1} E_{1, \text { eff }} a_{1} M(x)}{(E I)_{\mathrm{ef}}} \\
& =\frac{0.61(10462)(101)\left(41.8 \times 10^{6}\right)}{1.73 \times 10^{13}}=1.55 \mathrm{~N} / \mathrm{mm}^{2} .
\end{aligned}
$$

Concrete axial stress due to axial force for $F_{d, u}-F_{d, p}$ load combination,

$$
\begin{aligned}
\sigma_{1}(x) & =\frac{\gamma_{1} E_{1} a_{1} M(x)}{(E I)_{\mathrm{ef}}} \\
& =\frac{0.55(34000)(67.5)\left(61.9 \times 10^{6}\right)}{3.26 \times 10^{13}}=2.39 \mathrm{~N} / \mathrm{mm}^{2} .
\end{aligned}
$$

Total concrete axial stress due to axial force (superposition), $\sigma_{1, t o t}=1.55+2.39=3.94 \mathrm{~N} / \mathrm{mm}^{2}$.

Concrete axial stress due to bending moment for $F_{d, p}$ load combination,

$$
\begin{aligned}
\sigma_{m, 1}(x) & =\frac{1}{2} \cdot \frac{E_{1, \mathrm{eff}} h_{1} M(x)}{(E I)_{\mathrm{ef}}} \\
& =\frac{0.5(10462)(65)\left(41.8 \times 10^{6}\right)}{1.73 \times 10^{13}}=0.82 \mathrm{~N} / \mathrm{mm}^{2} .
\end{aligned}
$$

Concrete axial stress due to bending moment for $F_{d, u}-F_{d, p}$ load combination,

$$
\begin{aligned}
\sigma_{m, 1}(x) & =\frac{1}{2} \cdot \frac{E_{1} h_{1} M(x)}{(E I)_{\mathrm{ef}}} \\
& =\frac{0.5(34000)(65)\left(61.9 \times 10^{6}\right)}{3.26 \times 10^{13}}=2.10 \mathrm{~N} / \mathrm{mm}^{2} .
\end{aligned}
$$

Total concrete axial stress due to bending moment (superposition), $\sigma_{m, 1, \text { tot }}=0.82+2.10=2.92 \mathrm{~N} / \mathrm{mm}^{2}$.

Concrete total upper fibre stress, $\sigma_{c, \text { tot }}=\left|-\sigma_{1, \text { tot }}-\sigma_{m, 1, \text { tot }}\right|=$ $|-3.94-2.92|=6.86 \mathrm{~N} / \mathrm{mm}^{2}<f_{c d}=23.3 \mathrm{~N} / \mathrm{mm}^{2} \therefore$ satisfactory.

Concrete total lower fibre stress, $\sigma_{t, \text { tot }}=-\sigma_{1, \text { tot }}+\sigma_{m, 1, \text { tot }}=$ $-3.94+2.88=-1.02 \mathrm{~N} / \mathrm{mm}^{2}($ compression $)<f_{c t d}=$ $1.47 \mathrm{~N} / \mathrm{mm}^{2} \therefore$ satisfactory.

\section{Connection Strength Demand and Inequalities}

Maximum force in connection at support for $F_{d, p}$ load combination,

$$
\begin{aligned}
F_{(x=0)} & =\frac{\gamma_{1} E_{1, \mathrm{eff}} A_{1} a_{1} s_{\min }}{(E I)_{\mathrm{ef}}} \cdot V_{\max } \\
& =\frac{0.61(10462)(78000)(101)(831)}{1.73 \times 10^{13}} \times 20.9 \times 10^{3} \\
& =50.3 \mathrm{kN} .
\end{aligned}
$$

Maximum force in connection at support for $F_{d, u}-F_{d, p}$ load combination,

$$
\begin{aligned}
F_{(x=0)} & =\frac{\gamma_{1} E_{1} A_{1} a_{1} s_{\min }}{(E I)_{\mathrm{ef}}} \cdot V_{\max } \\
& =\frac{0.55(34000)(78000)(67.5)(831)}{3.26 \times 10^{13}} \times 31.0 \times 10^{3} \\
& =77.4 \mathrm{kN} .
\end{aligned}
$$

Total maximum force in connection at support (superposition), $F_{(x=0) \text {,tot }}=50.3+77.4=128 \mathrm{kN}<F_{d}=148 \mathrm{kN} \therefore$ satisfactory.

Force in connection at $L / 4$ for $F_{d, p}$ load combination,

$$
\begin{aligned}
F_{(x=L / 4)} & =\frac{\gamma_{1} E_{1, \mathrm{eff}} A_{1} a_{1} s_{\max }}{(E I)_{\mathrm{ef}}} \cdot V_{L / 4} \\
& =\frac{0.61(10462)(78000)(101)(1394)}{1.73 \times 10^{13}} \times 10.4 \times 10^{3} \\
& =42.2 \mathrm{kN} .
\end{aligned}
$$

Force in connection at $L / 4$ for $F_{d, u}-F_{d, p}$ load combination,

$$
\begin{aligned}
F_{(x=L / 4)} & =\frac{\gamma_{1} E_{1} A_{1} a_{1} s_{\max }}{(E I)_{\mathrm{ef}}} \cdot V_{L / 4} \\
& =\frac{0.55(34000)(78000)(67.5)(1394)}{3.26 \times 10^{13}} \times 15.5 \times 10^{3} \\
& =65.0 \mathrm{kN} .
\end{aligned}
$$

Total maximum force in connection at $L / 4$ (superposition), $F_{(x=0) \text {,tot }}=42.2+65.0=107 \mathrm{kN}<F_{d}=148 \mathrm{kN} \therefore$ satisfactory. 
(3b) Verification for Ultimate Limit State in the Long Term due to Permanent Load Condition

Only permanent load, $w=1.35 G=4.86 \mathrm{kN} / \mathrm{m}$.

Design bending moment, $M_{d}=w L^{2} / 8=38.9 \mathrm{kN} / \mathrm{m}$.

Design shear force, $V_{d}=w L / 2=19.4 \mathrm{kN}$.

Design shear force at $L / 4$ from end, $V_{L / 4}=9.70 \mathrm{kN}$.

Since a redistribution of forces takes place in the composite beam due to the different creep behaviour of the component materials (timber, concrete, and connection), the effective moduli are used in the equations.

Fictitious effective moduli accounting for time-dependent effects at final time, $t$, of analysis (the end of the service life, usually 50 years) as follows:

Effective modulus for concrete,

$$
\begin{aligned}
E_{1, \mathrm{eff}} & =\frac{E_{1}}{1+\phi\left(t_{\mathrm{inf}}, t_{0}\right)} \\
& =\frac{34000}{1+2.25}=10462 \mathrm{~N} / \mathrm{mm}^{2} .
\end{aligned}
$$

(same as in (3a));

Effective modulus for timber,

$$
\begin{aligned}
E_{2, \text { eff }} & =\frac{E_{2}}{1+k_{\text {def }}} \\
& =\frac{10700}{1+0.6}=6688 \mathrm{~N} / \mathrm{mm}^{2}
\end{aligned}
$$

(same as in (3a));

Effective slip modulus for connection at ULS,

$$
K_{u, \text { eff }}=\frac{K_{u}}{1+\phi_{f}\left(t-t_{0}\right)}=\frac{482857}{1+1.57}=187955 \mathrm{~N} / \mathrm{mm}^{2}
$$

(this is different from (3a) as reference to the serviceability slip modulus was made in (3a)).

Bending Stiffness Properties for Ultimate Limit State LongTerm Verification throughout the Service Life of the Structure are as follows:

Concrete gamma coefficient,

$a_{1}$ distance,

$$
\begin{aligned}
a_{1} & =\frac{E_{2, \mathrm{eff}} A_{2} H}{\gamma_{1} E_{1, \mathrm{eff}} A_{1}+E_{2, \mathrm{eff}} A_{2}} \\
& =\frac{6688(126 \times 400)(250)}{0.61(10462)(65 \times 1200)+(6688)(126 \times 400)} \\
& =101 \mathrm{~mm} ;
\end{aligned}
$$

$a_{2}$ distance,

$$
\begin{gathered}
a_{2}=\frac{\gamma_{1} E_{1, \mathrm{eff}} A_{1} H}{\gamma_{1} E_{1, \mathrm{eff}}} A_{1}+E_{2, \mathrm{eff}} A_{2} \text { or } \\
a_{2}=H-a_{1}=250-101=149 \mathrm{~mm} ;
\end{gathered}
$$

Effective flexural stiffness,

$$
\begin{aligned}
(E I)_{\mathrm{ef}}= & E_{1, \mathrm{eff}} I_{1}+E_{2, \mathrm{eff}} I_{2}+\gamma_{1} E_{1, \mathrm{eff}} A_{1} a_{1}^{2}+E_{2, \mathrm{eff}} A_{2} a_{2}^{2} \\
= & 10462\left(2.75 \times 10^{7}\right)+6688\left(6.72 \times 10^{8}\right) \\
& +0.61(10462)(78000)(101)^{2} \\
& +(6688)(50400)(149)^{2} \\
= & 1.73 \times 10^{13} \mathrm{~N} / \mathrm{mm}^{2} .
\end{aligned}
$$

\section{Timber Strength Demand and Inequalities}

Timber axial stress due to axial force,

$$
\begin{aligned}
\sigma_{2}(x) & =\frac{E_{2, \mathrm{eff}} a_{2} M(x)}{(E I)_{\mathrm{ef}}} \\
& =\frac{(6688)(149)\left(38.9 \times 10^{6}\right)}{1.73 \times 10^{13}}=2.24 \mathrm{~N} / \mathrm{mm}^{2} .
\end{aligned}
$$

Timber axial stress due to bending moment,

$$
\begin{aligned}
\sigma_{m, 2}(x) & =\frac{1}{2} \cdot \frac{E_{2, \mathrm{eff}} h_{2} M(x)}{(E I)_{\mathrm{ef}}} \\
& =\frac{0.5(6688)(400)\left(38.9 \times 10^{6}\right)}{1.73 \times 10^{13}}=3.01 \mathrm{~N} / \mathrm{mm}^{2} .
\end{aligned}
$$

Combined bending and tension ratio, $\sigma_{2} / f_{t, 0, d}+\sigma_{m, 2} /$ $f_{m, d}<=1 \sigma_{2} / f_{t, 0, d}+\sigma_{m, 2} / f_{m, d}=2.24 / 15+3.01 / 24=0.28<1$ $\therefore$ satisfactory.

Timber shear stress, with the simplified and conservative assumption that only the timber part resists shear:

$$
\begin{array}{r}
\tau_{d, \max }=1.5 \frac{V_{d}}{A_{2}}=1.5\left(\frac{19.4 \times 10^{3}}{50400}\right) \\
=0.58 \mathrm{~N} / \mathrm{mm}^{2}<f_{v, d}=7.36 \mathrm{~N} / \mathrm{mm}^{2} \\
\therefore \text { satisfactory. }
\end{array}
$$

Bearing of timber at support with a bearing length $l_{b}$ of $75 \mathrm{~mm}$,

$$
\begin{aligned}
& \sigma_{d, \text { max }}= \frac{V_{d}}{l_{b} b_{2}}=\frac{19.4 \times 10^{3}}{75 \times 126} \\
&=2.05 \mathrm{~N} / \mathrm{mm}^{2}<f_{c, 90, d}=6.00 \mathrm{~N} / \mathrm{mm}^{2} \\
& \therefore \text { satisfactory. }
\end{aligned}
$$

\section{Concrete Strength Demand and Inequalities}

Concrete axial stress due to axial force,

$$
\begin{aligned}
\sigma_{1}(x) & =\frac{\gamma_{1} E_{1, \mathrm{eff}} a_{1} M(x)}{(E I)_{\mathrm{ef}}} \\
& =\frac{0.61(10462)(101)\left(38.9 \times 10^{6}\right)}{1.73 \times 10^{13}}=1.45 \mathrm{~N} / \mathrm{mm}^{2} .
\end{aligned}
$$


Concrete axial stress due to bending moment,

$$
\begin{aligned}
\sigma_{m, 1}(x) & =\frac{1}{2} \cdot \frac{E_{1, \mathrm{eff}} h_{1} M(x)}{(E I)_{\mathrm{ef}}} \\
& =0.5(10462)(65)\left(38.9 \times 10^{6}\right) / 1.73 \times 10^{13} \\
& =0.77 \mathrm{~N} / \mathrm{mm}^{2}
\end{aligned}
$$

Concrete total upper fibre stress,

$$
\begin{aligned}
\sigma_{c, \text { tot }, t} & =\left|-\sigma_{1}-\sigma_{m, 1}\right| \\
& =|-1.45-0.77|=2.22 \mathrm{~N} / \mathrm{mm}^{2} \\
& <f_{c d}=23.3 \mathrm{~N} / \mathrm{mm}^{2} \therefore \text { satisfactory. }
\end{aligned}
$$

Concrete total lower fibre stress,

$$
\begin{aligned}
\sigma_{t, \mathrm{tot}} & =-\sigma_{1}+\sigma_{m, 1} \\
& =-1.45+0.77=-0.68 \mathrm{~N} / \mathrm{mm}^{2}(\text { compression }) \\
& <f_{c t d}=1.47 \mathrm{~N} / \mathrm{mm}^{2} \therefore \text { satisfactory. }
\end{aligned}
$$

\section{Connection Strength Demand and Inequalities}

Shear force in connection at maximum shear,

$$
\begin{aligned}
F_{(x=0)} & =\frac{\gamma_{1} E_{1, \mathrm{eff}} A_{1} a_{1} s_{\min }}{(E I)_{\mathrm{ef}}} \cdot V_{\max } \\
& =\frac{0.61(10462)(78000)(101)(831)}{1.73 \times 10^{13}} \times 19.4 \times 10^{3} \\
& =46.9 \mathrm{kN}<F_{d}=111 \mathrm{kN} \therefore \text { satisfactory. }
\end{aligned}
$$

Shear force in connection at $L / 4$,

$$
\begin{aligned}
F_{(x=L / 4)} & =\frac{\gamma_{1} E_{1, \mathrm{eff}} A_{1} a_{1} s_{\mathrm{max}}}{(E I)_{\mathrm{ef}}} \cdot V_{L / 4} \\
& =\frac{0.61(10462)(78000)(101)(1394)}{1.73 \times 10^{13}} \times 9.70 \times 10^{3} \\
& =39.3 \mathrm{kN}<F_{d}=111 \mathrm{kN} \therefore \text { satisfactory. }
\end{aligned}
$$

Remark 2. If the floor had been only made of timber, the choice of the most critical load conditions between $1.35 \mathrm{G}$ and $1.35 G+1.5 Q$ could have been made a priori by comparing the load $-k_{\text {mod }}$ ratios and choosing the load condition with the largest value: $(1.35 G) / k_{\bmod }=4.86 / 0.6=8.1 \mathrm{kN} / \mathrm{m}$; $(1.35 G+1.5 Q) / k_{\bmod }=13.0 / 0.8=16.25 \mathrm{kN} / \mathrm{m}$; hence, the load condition $1.35 G+1.5 Q$ is more critical. However, since the structure is made of a timber-concrete composite beam, the aforementioned criterion is, strictly speaking, not applicable. Nevertheless, it can be used to obtain a first qualitative indication, particularly when the difference, like in this case, is great and suggests that only one load condition will be significant.
(4) Verification for Serviceability Limit State in the Long Term Bending Stiffness Properties for Serviceability Limit State LongTerm Verifications throughout the Service Life of the Structure as follows:

Concrete gamma coefficient,

$$
\begin{aligned}
\gamma_{1} & =\frac{1}{1+\left(\pi^{2} E_{1, \text { eff }} A_{1} s_{\mathrm{ef}} / K_{s, \text { eff }}{ }^{2}\right)} \\
& =\frac{1}{1+\left(\pi^{2}(10462)(65 \times 1200) 972 / 192474(8000)^{2}\right)} \\
& =0.061 ;
\end{aligned}
$$

$a_{1}$ distance,

$$
\begin{aligned}
a_{1} & =\frac{E_{2, \mathrm{eff}} A_{2} H}{\gamma_{1} E_{1, \mathrm{eff}} A_{1}+E_{2, \mathrm{eff}} A_{2}} \\
& =\frac{6688(126 \times 400)(250)}{0.61(10462)(65 \times 1200)+(6688)(126 \times 400)} \\
& =101 \mathrm{~mm} ;
\end{aligned}
$$

$a_{2}$ distance,

$$
\begin{gathered}
a_{2}=\frac{\gamma_{1} E_{1, \mathrm{eff}} A_{1} H}{\gamma_{1} E_{1, \mathrm{eff}} A_{1}+E_{2, \mathrm{eff}} A_{2}} \text { or } \\
a_{2}=H-a_{1}=250-101=149 \mathrm{~mm} ;
\end{gathered}
$$

Effective flexural stiffness,

$$
\begin{aligned}
(E I)_{\mathrm{ef}}= & E_{1, \mathrm{eff}} I_{1}+E_{2, \mathrm{eff}} I_{2}+\gamma_{1} E_{1, \mathrm{eff}} A_{1} a_{1}^{2}+E_{2, \mathrm{eff}} A_{2} a_{2}^{2} \\
= & 10462\left(2.75 \times 10^{7}\right)+6688\left(6.72 \times 10^{8}\right) \\
& +0.61(10462)(78000)(101)^{2} \\
& +(6688)(50400)(149)^{2} \\
= & 1.73 \times 10^{13} \mathrm{~N} / \mathrm{mm}^{2} .
\end{aligned}
$$

\section{Deflection Inequalities}

Quasi-permanent part of the load, $F_{d, p}=G+\psi_{2} Q=3.6+$ $(0.3 \times 5.4)=5.22 \mathrm{kN} / \mathrm{m}$.

Mid-span long-term deflection due to quasi-permanent part of the load,

$$
u_{\mathrm{final}, d, p}=\frac{5 F_{d, p} l^{4}}{384(E I)_{\mathrm{ef}}}=\frac{5(5.22)(8000)^{4}}{384\left(1.73 \times 10^{13}\right)}=16.1 \mathrm{~mm} \text {. }
$$

Difference between the rare and the quasi-permanent load, $F_{d, r}-F_{d, p}=\left(1-\psi_{2}\right) Q=(1-0.3) \times 5.4=3.78 \mathrm{kN} / \mathrm{m}$. load,

Instantaneous mid-span deflection due to the $F_{d, r}-F_{d, p}$

$$
\begin{aligned}
u_{\text {inst, } d, r-d, p} & =\frac{5\left(F_{d, r}-F_{d, p}\right) l^{4}}{384 E I_{\mathrm{ef}}} \\
& =\frac{5(3.78)(8000)^{4}}{384\left(1.73 \times 10^{13}\right)}=11.6 \mathrm{~mm} .
\end{aligned}
$$


Total long-term deflection, $u_{\text {final, } d, p}+u_{\text {inst, },, r-d, p}=16.1+$ $11.6=27.7 \mathrm{~mm}<u_{\text {allow }}=\operatorname{span} / 250=32.0 \mathrm{~mm} \therefore$ satisfactory.

\section{Notation}

A : $\quad$ Cross-sectional area (with subscripts 1 and 2 for concrete and timber, resp.)

E: $\quad$ Modulus of elasticity (with subscripts 1 and 2 for concrete and timber, resp.)

$E_{\text {eff: }} \quad$ Effective modulus (with subscripts 1 and 2 for concrete and timber, resp.)

$(E I)_{\text {eff: }}$ Effective flexural stiffness of composite beam

$F_{d, u}$ : Design maximum load condition at ultimate limit state

$F_{d, p}$ : Design quasi-permanent load condition at serviceability limit state

$F_{d, r}: \quad$ Design rare load condition at serviceability limit state

$F d *$ : Design load condition

$F$ : $\quad$ Shear strength capacity of connection (with subscripts $k$ and $d$ for characteristic and design values, resp.)

$F^{*}$ : Shear force demand in the connection

$G$ : $\quad$ Permanent load or action

$H$ : Distance between the centroid of concrete and timber sections

I: $\quad$ Second moment of area (with subscripts 1 and 2 for concrete and timber, resp.)

K: $\quad$ Secant slip modulus of connection (with subscripts $s$ and $u$ for serviceability and ultimate limit states, resp.)

$K_{\text {eff }}: \quad$ Effective slip modulus of connection

$M^{*}$ : Bending moment demand (with subscripts 1 and 2 for concrete and timber, resp.)

$M_{R}$ : Bending design capacity or resistance

$N^{*}: \quad$ Axial force demand (with subscripts 1 and 2 for concrete and timber, resp.)

$N_{R}$ : Tensile design capacity or resistance

Q: $\quad$ Variable action or imposed load

$R_{m}$ : Mean shear strength of connection obtained from push-out test

$V_{2}^{*}: \quad$ Shear force demand in timber

$Z$ : $\quad$ Section modulus

$a$ : Distance between the neutral axis of the timber-concrete composite section and the centroid of the concrete or timber section denoted by subscripts 1 and 2, respectively

b: $\quad$ Section breadth (with subscripts 1 and 2 for concrete and timber, resp.)

$f_{c, d}$ : Design compressive strength of concrete

$f_{c t d}$ : Design tensile strength of concrete

$f_{d}$ : Design strength of timber (with subscripts $t ; m ; v ; c, 0$, and $c$; 90 for tensile, bending, shear, and compression parallel and perpendicular to grain, resp.)

$h$ : $\quad$ Section depth (with subscripts 1 and 2 for concrete and timber, resp.)

$k_{\text {def }}$ : Creep deformation factor of timber $k_{\text {mod }}$ : Modification factor for duration of load and moisture content

l: $\quad$ Span length

$s$ : Spacing of connectors (with subscripts eff, min and max for effective, minimum, and maximum spacing, resp.)

$u: \quad$ Vertical deflection

$v: \quad$ Slip of connection measured in push-out test

$\phi\left(t, t_{0}\right)$ : Creep coefficient (with subscripts 1,2 , and $f$ for concrete, timber, and connection, resp.)

$\gamma: \quad$ Gamma coefficient (with subscripts 1 and 2 for concrete and timber, resp.)

$\gamma_{m}$ : $\quad$ Partial factor for material property

$\psi_{2}$ : Partial factor for quasi-permanent value of a variable load or action

$\sigma: \quad$ Stress due to axial force (with subscripts 1 and 2 for concrete and timber, resp.)

$\sigma_{m}$ : Stress due to bending moment (with subscripts 1 and 2 for concrete and timber, resp.).

\section{Acknowledgment}

The authors would like to acknowledge Universiti Tun Hussein Onn Malaysia (UTHM) for the sponsorship of the article processing fees through the Fundamental Research Grant Scheme under the Malaysian Ministry of Higher Education.

\section{References}

[1] A. Ceccotti, Timber-Concrete Composite Structures, Timber Engineering STEP 2, edited by Hans Blass et al., Centrum Hout, 1st edition, 1995.

[2] D. Yeoh, M. Fragiacomo, A. Buchanan, and C. Gerber, "Preliminary research towards a semi-prefabricated LVLconcrete composite floor system for the Australasian market," Australian Journal of Structural Engineering, vol. 9, no. 3, pp. 225-240, 2009.

[3] D. Yeoh, M. Fragiacomo, and B. Deam, "Experimental behaviour of LVL-concrete composite floor beams at strength limit state," Engineering Structures, vol. 33, no. 9, pp. 26972707, 2011.

[4] D. Yeoh, M. Fragiacomo, M. De Franceschi, and A. H. Buchanan, "Experimental tests of notched and plate connectors for LVL-concrete composite beams," Journal of Structural Engineering, vol. 137, no. 2, pp. 261-269, 2011.

[5] A. Ceccotti, "Composite concrete-timber structures," Progress in Structural Engineering and Materials, vol. 4, no. 3, pp. 264275, 2002.

[6] A. Ceccotti, M. Fragiacomo, and R. M. Gutkowski, "Design of timber-concrete composite structures according to EC5-2002 version," in Proceedings of the Thirty-Five of the Working Commission W18-Timber Structures, CIB, International Council for Research and Innovation, CIB-W18/35, Kyoto, Japan, 2002.

[7] P. Clouston, L. A. Bathon, and A. Schreyer, "Shear and bending performance of a novel wood-concrete composite system," Journal of Structural Engineering, vol. 131, no. 9, pp. 14041412, 2005.

[8] E. Lukaszewska, H. Johnsson, and M. Fragiacomo, "Performance of connections for prefabricated timber-concrete 
composite floors," Materials and Structures, vol. 41, no. 9, pp. 1533-1550, 2008.

[9] M. Fragiacomo and E. Lukaszewska, "Development of prefabricated timber-concrete composite floor systems," Structures and Buildings, vol. 164, no. 2, pp. 117-129, 2011.

[10] CEN Comité Européen de Normalisation, Eurocode 5: Design of Timber Structures_Part 2: Bridges, Brussels, Belgium, 2004.

[11] CEN Comité Européen de Normalisation, Eurocode 5: Design of Timber Structures-General Rules and Rules for BuildingsPart 1-1, Brussels, Belgium, 2004.

[12] K. Möhler, On the Load Carrying Behavior of Beams and Columns of Compound Sections with Flexible Connections, Habilitation, Technical University of Karlsruhe, 1956.

[13] D. Yeoh, M. Fragiacomo, M. De Franceschi, and H. B. Koh, "The state-of-the-art on timber-concrete composite structures-a literature review," Journal Structural Engineering, vol. 137, no. 10, pp. 1085-1095, 2011.

[14] M. P. Newcombe, W. A. Van Beerschoten, D. Carradine, S. Pampanin, and A. H. Buchanan, "In-plane experimental testing of timber-concrete composite floor diaphragms," Journal of Structural Engineering, vol. 136, no. 11, pp. 1461-1468, 2010.

[15] EXPAN Structural Timber Solutions, "Feature story," 2012, http://www.expan.co.nz/EXPAN-building-University-Canterbury-campus-stunning-showcase-what-structu__I.979.

[16] D. M. Carradine, M. P. Newcombe, and A. H. Buchanan, "Using screws for structural applications in laminated veneer lumber," in Proceedings of the Fourty-Two of the Working Commission W18-Timber Structures, CIB, International Council for Research and Innovation, no. CIB-W18/42-7-7, Dübendorf, Switzerland, 2009.

[17] M. Newcombe, W. A. van-Beerschoten, D. Carradine et al., "In-plane experimental testing of timber-concrete composite floor diaphragms," in Proceedings of the Society of Earthquake Engineering Conference, Christchurch, New Zealand, 2009.

[18] T. Smith, S. Pampanin, M. Fragiacomo, and A. Buchanan, "Design and construction of prestressed timber buildings for seismic areas," in Proceedings of the 10th World Conference on Timber Engineering, Miyazaki, Japan, 2008.

[19] T. Smith, M. Fragiacomo, S. Pampanin, and A. H. Buchanan, "Construction time and cost for post-tensioned timber buildings," Proceedings of Institution of Civil Engineers, vol. 162, no. 4, pp. 141-149, 2009.

[20] EXPAN Structural Timber Solutions, "Massey buildingcollege of creative arts building," 2012, http://www.expan.co .nz/Massey-buildling__I.1722_N.10.

[21] AS/SNZ Standards Australia and Standards New Zealand, "Structural design actions: general principles," AS/NZS 1170 Part 0, 2002.

[22] CEN Comité Européen de Normalisation, Eurocode-Basis of Structural Design, Brussels, Belgium, 2002.

[23] M. Fragiacomo, "Long-term behavior of timber-concrete composite beams. II: numerical analysis and simplified evaluation," Journal of Structural Engineering, vol. 132, no. 1, pp. 23-33, 2006.

[24] J. Schänzlin and M. Fragiacomo, "Extension of EC5 Annex $\mathrm{B}$ formulas for the design of timber-concrete composite structures," in Proceedings of the Forty of the Working Commission W18-Timber Structures, CIB, International Council for Research and Innovation, no. CIB-W18/40-10-1, 2007.

[25] M. Fragiacomo and J. Schänzlin, "A Proposal to Account for Concrete Shrinkage and Environmental Strains in Design of
Timber-Concrete Composite Beams," Journal of Structural Engineering, 2012.

[26] CEN Comité Européen de Normalisation, Timber StructuresJoints Made with Mechanical Fasteners-General Principles for the Determination of Strength and Deformation Characteristics, EN 26891, Brussels, Belgium, 1991.

[27] K. W. Johansen, “Theory of timber connections," International Association of Bridge and Structural Engineering, pp. 249-262, 1949.

[28] A. Ceccotti, M. Fragiacomo, and S. Giordano, "Long-term and collapse tests on a timber-concrete composite beam with glued-in connection," Materials and Structures, vol. 40, no. 1, pp. 15-25, 2007.

[29] E. Lukaszewska, M. Fragiacomo, and A. Frangi, "Evaluation of the slip modulus for ultimate limit state verifications of timber-concrete composite structures," in Proceedings of the Forty of the Working Commission W18-Timber Structures, CIB, International Council for Research and Innovation, no. CIBW18/40-7-5, 2007.

[30] CEN Comité Européen de Normalisation, Eurocode 2-Design of Concrete Structures-Part 1-1: General Rules and Rules for Buildings, Brussels, Belgium, 2004.

[31] Carter Holt Harvey, LVL Specific Design Information, Technical Bulletin, 2009.

[32] D. Yeoh, Behaviour and Design of Timber-Concrete Composite Floor System [Ph.D. thesis], University of Canterbury, 2010.

[33] D. Gaunt and B. Penellum, "Phase 1 truform in-grade testing for carter holt harvey," Report TE03-037, New Zealand Forest Research Institute Limited, 2004.

[34] B. Di Lenardo, Study Develops Vibration Criteria for WoodBased Floor Joists, Construction Innovation, 1998. 

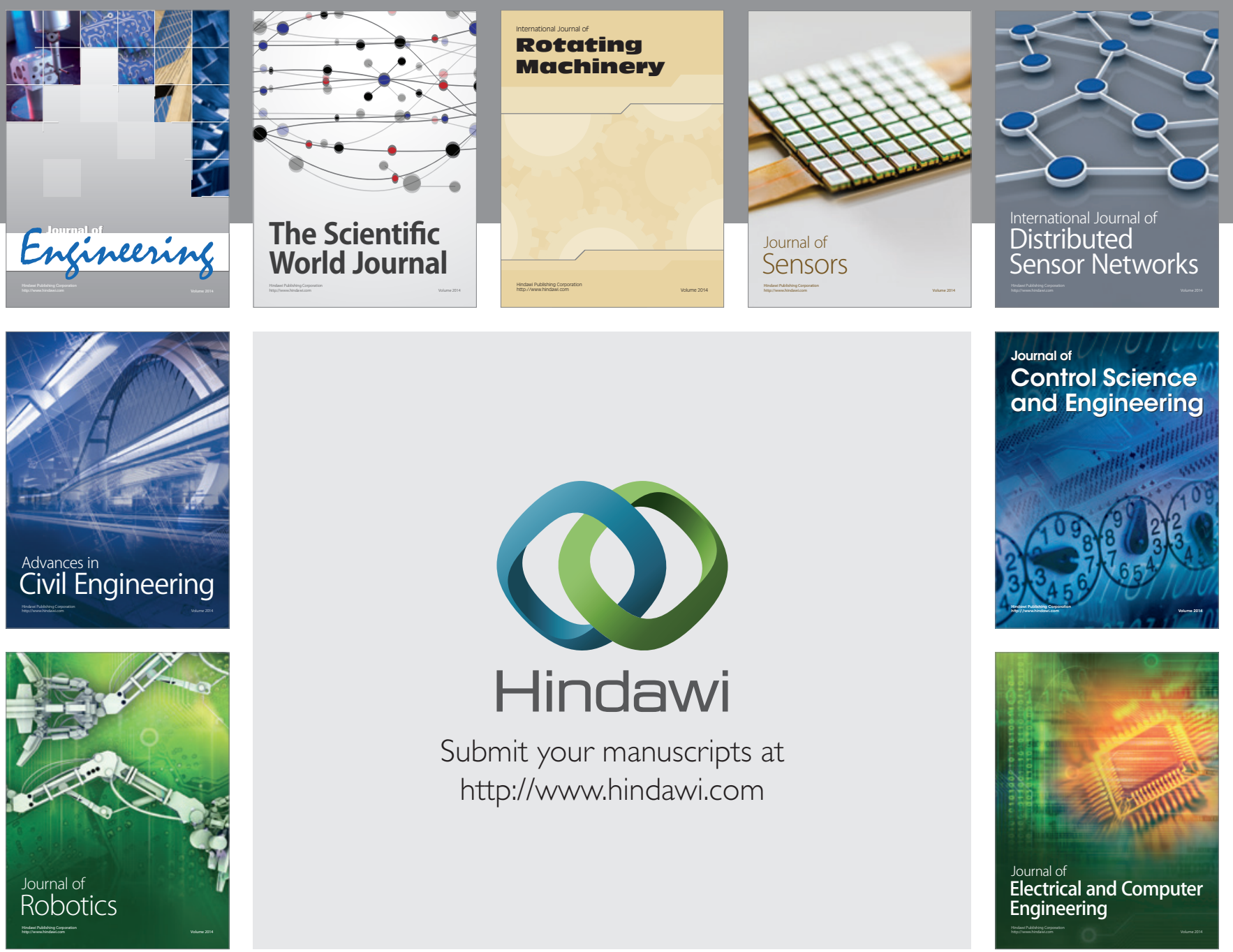

Submit your manuscripts at

http://www.hindawi.com
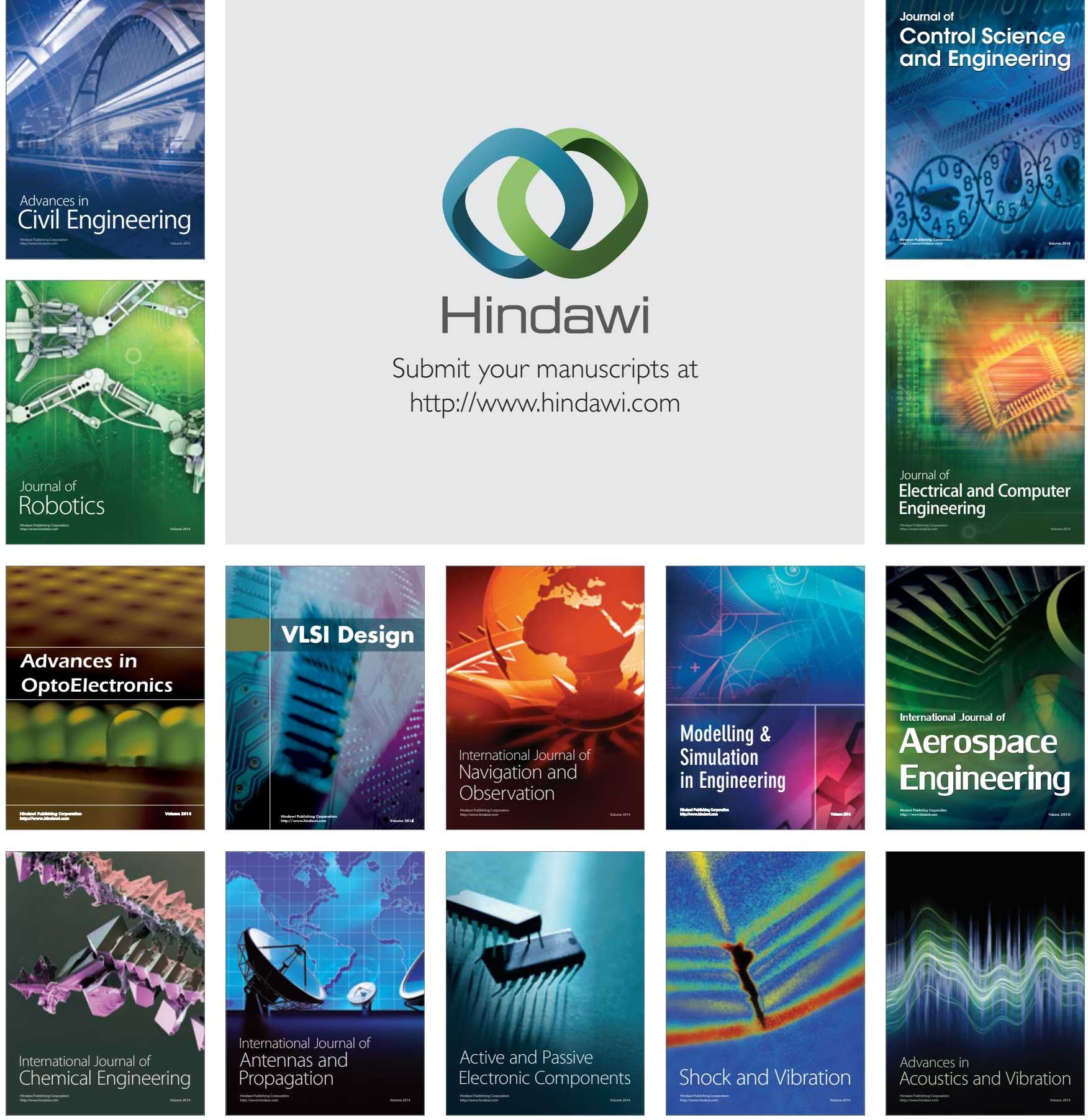